\title{
ENGINEERED CREDIT DEFAULT SWAPS: INNOVATIVE OR MANIPULATIVE?
}

\author{
GINA-GAIL S. FLETCHER*
}

Credit default swaps ("CDS") are, once again, making waves. Maligned for their role in the 2008 financial crisis and condemned by the Vatican, investors are once more utilizing CDS to achieve results of questionable market benefit. A CDS is a financial contract that allows investors to "bet" on whether a borrower will default on its loan. However, rather than waiting to see how their bets pan out, some CDS counterparties are collaborating with financially distressed borrowers to guarantee the profitability of their CDS positions-"engineering" the CDS' outcome. Under the CDS contract, these collaborations are not prohibited, yet they have roiled the CDS market, leading some market participants to view the collaborations as a sign that CDS are little more than a rigged game. Conversely, some view "engineered CDS transactions" as an innovative form of financing for distressed companies. As engineered CDS transactions proliferate in the market, it becomes increasingly prudent to look beyond their contractual acceptability to assess whether, from a legal point of view, these transactions are permissible.

Engineered CDS transactions demonstrate the challenges that the existing legal and nonlegal framework face in effectively responding to new forms of market distortion. This Article examines the costs and benefits of engineered CDS transactions on the market as a precursor to determining whether legal intervention is needed. Assessment of the relative costs and benefits of engineered transactions indicates that despite their innovativeness, engineered CDS transactions are largely detrimental to the markets because they impose costs on actors unaffiliated with the CDS market and, more broadly, destroy public trust in the financial markets. Yet, despite their associated harms, legally, engineered transactions exist in a gray space. This Article analyzes the phenomenon of engineered CDS transactions, assessing the capacity of applicable legal frameworks, private standards, and market discipline to address these transactions, and finds each to be lacking. Consequently, this Article proposes a range of responses, including modernization of the existing anti-manipulation framework, to mitigate the harm and collateral consequences that stem from engineered CDS transactions.

INTRODUCTION 103

I. AN OVERVIEW OF CREDIT DEFAULT SWAPS. 108

* Copyright $(\underset{2}{ } 2019$ by Gina-Gail S. Fletcher, Associate Professor, Indiana University Maurer School of Law. J.D. Cornell Law School. B.A. Mount Holyoke College. For helpful comments, I would like to thank the participants of the Sixth Annual Workshop for Corporate \& Securities Litigation, Boston College Law School Regulation and Markets Workshop, Notre Dame Law School Governance Roundtable, Indiana University Maurer School of Law faculty workshop, and 2019 AALS Business Law Section Junior Workshop. I would also like to thank Felix Chang, Kevin E. Davis, Jessica M. Eaglin, Gregory C. Edwards, Joe Grundfest, Kristin N. Johnson, Jeremy Kress, Orly Lobel, Patricia McCoy, Donna Nagy, Shu-Yi Oei, Aviva Orenstein, Elizabeth Pollman, Diane Ring, Usha Rodrigues, Veronica Root Martinez, Paolo Saguato, and Anne Tucker. Sabienne Brutus, Alyssa Gerstner, Lucrecia Guerra Galdamez, Emily Guillaume, and Zoe Gyampoh provided invaluable research assistance. All errors and omission are my own. 


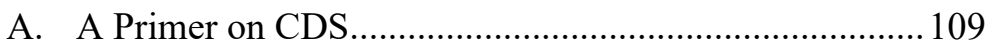

B. The CDS Market.......................................................... 113

C. The Role of ISDA................................................................ 116

II. ENGINEERED CREDIT DEFAULT SWAPS: TYPOLOGY AND

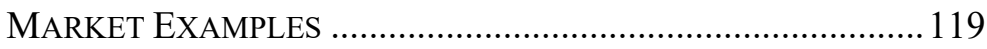

A. Manufacturing Default: The Cases of Codere

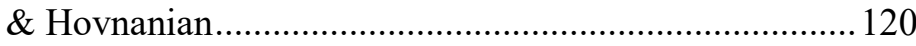

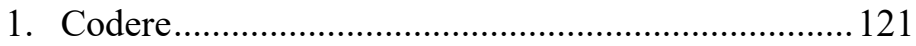

2. Hovnanian.................................................................. 122

B. Avoiding Default: The Case of RadioShack ..................124

C. Negating Default: The Case of McClatchy ....................127

III. ASSESSING BENEFITS, COSTS, AND

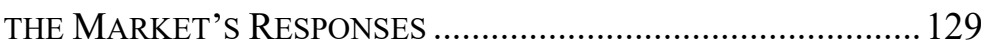

A. The Consequences for the Parties.................................. 130

B. The Consequences for Third Parties.............................. 132

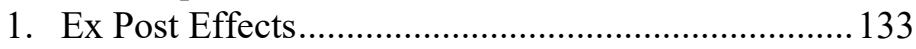

a. Pricing Inefficiency in the CDS Market............. 133

b. Costs to Non-CDS Traders.................................. 136

2. Ex Ante Effects ......................................................... 137

a. Decreased Liquidity ............................................ 137

b. Impaired Market Integrity ................................. 139

c. Reduced Credit Market Liquidity ...................... 140

C. The Limits of the Market's Responses ............................ 142

1. Bilateral Amendments to the Master Agreement...... 142

2. Market Discipline ...................................................... 143

IV. APPLYING LAW TO ENGINEERED CDS ................................. 145

A. Statutory Law: Anti-Manipulation Laws and

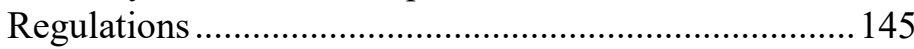

1. Anti-Manipulation Framework .................................146

a. The SEC and the Exchange Act .........................146

b. The CFTC and the CEA .................................... 147

2. Application to Engineered CDS ............................. 148

a. Price Artificiality .............................................. 148

b. Fraud and Material Misstatements ...................... 149

c. Manipulative Intent ..........................................150

B. Contract Common Law ................................................. 151

C. Private Law: ISDA's Rules and Governance ..................154

V. PATHWAYS FORWARD: ADDRESSING THE GAP ...................... 157

A. Broadening the Scope of ISDA's Amendments .............. 158

B. (Re)Establishing Good Faith Obligations.......................161

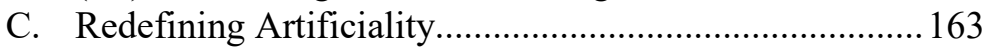

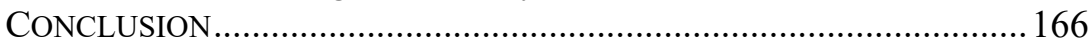




\section{INTRODUCTION}

\section{"[B]etting on a 'sure thing' is anathema to the ideal of 'fair and honest markets., ',}

In early 2018, regulatory and media attention turned to the credit default swap ("CDS") market as an unusual financing agreement between Hovnanian Enterprises Inc. ("Hovnanian”), a heavily-indebted company, and GSO Capital Partners ("GSO"), a division of Blackstone Group, was announced. ${ }^{2}$ Per the agreement, in exchange for financing on favorable terms from GSO, Hovnanian agreed to voluntarily default on an upcoming interest payment. ${ }^{3}$ Importantly, Hovnanian's voluntary default would trigger payoffs to traders who purchased CDS protection expecting that Hovnanian would default. Among these CDS counterparties was GSO, who stood to gain a sizable payout on its CDS positions if Hovnanian defaulted. ${ }^{4}$ In short, Hovnanian and GSO collaborated to guarantee the profitability of the latter's CDS positions in exchange for cheap financing for the former. Working together, they "engineered" the outcome of the CDS contract and eliminated all market uncertainty of whether Hovnanian would default. Despite its seeming peculiarity, the GSO-Hovnanian transaction is one of the latest examples of what this Article defines as "engineered transactions" in the CDS market.

Once known only to sophisticated market actors, CDS gained widespread notoriety during the 2008 financial crisis because of their role in the collapse of Lehman Brothers and the near-collapse of American Insurance Group. ${ }^{5}$ In simple yet incomplete terms, a CDS is an insurance-

1588 F.2d 1358, 1362 (2d Cir. 1978).

2 See, e.g., Mary Childs, The Hedge Fund Skirmish that Could Kill the CDS Market, BARRON's (Jan. 26, 2018), https://www.barrons.com/articles/the-hedge-fund-battle-thatcould-kill-the-cds-market-1517013136; Andrew Scurria, Blackstone Stands Down on Hovnanian Swaps Wager, WALl ST. J. (May 30, 2018), https://www.wsj.com/articles/blackstone-standsdown-on-hovnanian-swaps-wager-1527722945.

3 See Sridhar Natarajan \& Chris Dolmetsch, Hedge Fund Sues Hovnanian, Blackstone's GSO Over 'Manipulation,' BloOMBerg (Jan. 11, 2018, 2:30 PM), https://www.bloomberg.com/news/articles/2018-01-11/hedge-fund-solus-sues-gso-hovnanianover-cds-manipulation (discussing the agreement between Hovnanian and GSO).

4 See Joe Rennison, GSO Bought \$330m of Protection on Hovnanian Before Controversial Refi Deal, FIN. TIMES (Jan. 25, 2018), https://www.ft.com/content/304902dc-022a-11e8-96509c0ad2d7c5b5 (describing that the deal between GSO and Hovnanian "builds-in [sic] a condition that Hovnanian must default on a small portion of its existing bonds, with the aim of triggering a windfall payout for GSO").

5 See Kristin N. Johnson, Things Fall Apart: Regulating the Credit Default Swap Commons, 82 U. COLO. L. REV. 167, 170 (2011) ("Credit default swaps captured the national spotlight following their role in the largest bankruptcy in the history of the United States. On September 14, 2008, ... Lehman Brothers Holdings, Inc. ('Lehmann Brothers') declared bankruptcy."); Adam Davidson, How AIG Fell Apart, REUTERS (Sept. 18, 2008, 6:49 PM), https://www.reuters.com/article/us-how-aig-fell-apart-idUSMAR85972720080918 (detailing how 
like financial contract that transfers the risk of default of a debt issuer, such as a corporation, municipality, or sovereign, between counterparties. ${ }^{6}$ With fire insurance, for example, a homeowner pays monthly premiums to her insurance company and, in exchange, the insurance company agrees to compensate her if her house burns down. By analogy, with a CDS, one party (the "protection buyer") pays periodic premiums to another party (the "protection seller") and, in exchange, the protection seller agrees to compensate the protection buyer in the event the third-party debtor (the "issuer" or "company") defaults on the debt underlying the CDS (the "underlying"). ${ }^{7}$ Thus, the protection seller prefers that the issuer remain solvent (at least during the term of the CDS), and the protection buyer prefers that the issuer default. With engineered transactions, CDS traders are transforming their preferred outcomes into guarantees. Traders are gaming their CDS contracts to guarantee that they win- just as GSO proposed to do through its financing arrangement with Hovnanian.

Engineered transactions are a recent phenomenon and have resulted in renewed scrutiny of the controversial CDS markets. Some commentators consider engineered transactions positively-they allow distressed companies to access favorable and much-needed funding, thereby further increasing liquidity in the credit markets. ${ }^{8}$ To these commentators, to the extent engineered transactions harm anyone, their impact is limited to large, sophisticated actors, and engineering is merely another cost of doing business in the CDS markets. ${ }^{9}$ On the other hand, some view engineered transactions as unfair financial arrangements that violate market expectations of how CDS payoffs are determined, bypassing the market and its attendant uncertainties. ${ }^{10}$ Indeed, some market participants have

AIG's use of CDS contributed to its demise).

6 See Practical LaW Fin., Resource ID No. 0-386-8130, Credit Derivatives: OVERVIEW (US), Westlaw (database updated Jan. 22, 2016) (explaining that in a bilateral singlename CDS, a party buys credit protection "against the credit risk of a third party," known as the reference entity, which can be a corporation or a sovereign nation, among others).

7 See Kent Cherny \& Ben R. Craig, Credit Default Swaps and Their Market Function, FeD. RES. BANK CLEVELAND (July 9, 2009), https://www.clevelandfed.org/newsroom-andevents/publications/economic-commentary/economic-commentary-archives/2009-economiccommentaries/ec-20090709-credit-default-swaps-and-their-market-function.aspx ("In a typical transaction, the seller of the protection takes on the credit risk associated with a reference entity in return for a quarterly premium paid by the buyer.").

8 See Matt Levine, When Cleverness Becomes Manipulation, BloOMBERG OPINION (Apr. 26, 2018, 10:27 AM), https://www.bloomberg.com/view/articles/2018-04-26/when-clevernessbecomes-manipulation (explaining that there are people who consider these types of transactions to be an opportunity to transform a "zero-sum derivatives bet" into "an actual loan to an actual company that actually needed the money").

9 See id. (criticizing the classification of engineered transactions as market manipulation).

10 See Mary Childs, Judge Denies Injunction Request for Fancy CDS Transaction, BARRON's (Jan. 29, 2018), https://www.barrons.com/articles/congratulations-hovnanian-gso-judge-deniesinjunction-request-for-fancy-cds-transaction-1517256266 (explaining why the losers in these kinds of transactions describe them as akin to "burning your neighbor's house down to collect the 
expressed doubts that the CDS market can coexist with engineered transactions, since these transactions undermine the utility of CDS as risk mitigation tools. ${ }^{11}$ As the markets grapple with the effects and collateral consequences of engineered CDS transactions, important questions arise as to the advisability of allowing these transactions to continue to exist in the markets and, importantly, their legality. ${ }^{12}$

Engineered transactions present the CDS market with an interesting and perplexing conundrum - although they seem improper, they are not impermissible under the existing terms of the CDS contract, a conclusion that the International Swaps Dealers Association ("ISDA") supported. ${ }^{13}$ ISDA is a private, non-governmental trade association that drafts the standard-form CDS contract, including the processes by which it is determined whether a CDS payoff has been triggered. ${ }^{14}$ Despite expressing displeasure with the practice of engineered CDS transactions, ISDA has stated that these transactions are contractually permissible because CDS counterparties are allowed to act in their own self-interests. ${ }^{15}$ Furthermore, although both the Commodity Futures Trading Commission ("CFTC") and Securities Exchange Commission ("SEC"), who have regulatory authority over the CDS market, view engineered CDS transactions as market

insurance").

11 See Claire Boston \& Sridhar Natarajan, Blackstone, Solus Settle Fight over Hovnanian CDS Trade, BlOOMBERG (May 30, 2018), https://www.bloomberg.com/news/articles/2018-0530/hovnanian-pays-overdue-interest-on-bonds-within-grace-period (stating that CDS contracts "can become almost meaningless if a [counterparty] can create or prevent a payout on the contracts just by loaning relatively small amounts of money to a company").

12 See Press Release, CFTC Divs. of Clearing \& Risk, Mkt. Oversight, \& Swap Dealer \& Intermediary Oversight, Statement on Manufactured Credit Events (Apr. 24, 2018) [hereinafter CFTC Press Release], https://www.cftc.gov/PressRoom/SpeechesTestimony/divisionsstatement042418 ("Manufactured credit events may constitute market manipulation and may severely damage the integrity of the CDS markets...."); Matt Levine, Another Weird Deal Upsets CDS Traders, BLOOMBERG OPINION (May 1, 2018, 9:59 AM), https://www.bloomberg.com/view/articles/2018-05-01/anotherweird-deal-upsets-cds-traders (quoting Mike Terwilliger, a money manager at Resource America Inc., as saying that "CDS is being manipulated to the point that it potentially invalidates the product").

13 This was true at the time of the transactions, but amendments have since been proposed and adopted. See infra Section IV.C for a discussion of changes to the Master Agreement.

14 See generally Mission Statement, InT'L SWAPS \& DERIVATIVES Ass'N, https://www.isda.org/mission-statement (last visited Mar. 12, 2019) (describing its mission statement as "foster[ing] safe and efficient derivatives markets to facilitate effective risk management for all users of derivative products"). For additional context, see infra note 67 and accompanying text.

15 See Press Release, Int'l Swaps \& Derivatives Ass'n, ISDA Board Statement on Narrowly Tailored Credit Events (Apr. 11, 2018) (stating that amendments to the ISDA Credit Derivatives Definition could occur because "narrowly tailored defaults ... designed to result in CDS payments that do not reflect the creditworthiness of the underlying corporate borrower ... could negatively impact the ... overall CDS market"). But see discussion infra Section IV.C (discussing ISDA's proposed amendment to the CDS contract to prohibit one form of engineered transactions). 
manipulation, it is debatable whether this assertion is legally supported. ${ }^{16}$ Engineered CDS transactions do not involve fraud or misrepresentation, and the parties involved typically comply with their obligations to disclose material information once they have agreed to the terms of the transaction. ${ }^{17}$ Thus, engineered transactions exist in a legal gap - not prohibited under private contract law and beyond the scope of statutory proscriptions.

This Article provides an in-depth legal analysis of engineered CDS transactions and engages with the ongoing debate regarding their costs and legality. This Article argues that the benefits of engineered CDS transactions to distressed issuers notwithstanding, they impose significant externalities on the market, and thus external intervention is required to minimize the ex post and ex ante consequences to third parties. However, this Article disagrees with the conclusory assessment of the CFTC and others that engineered CDS transactions constitute market manipulation under existing anti-manipulation laws. Rather, these transactions, like other forms of financial innovation, are beyond the reach of existing public laws and private rules. Further, given the accompanying negative externalities, it is necessary to curtail the occurrence of engineered CDS transactions within the market and deter market actors from engaging in these transactions.

This Article makes three important contributions to legal scholarship related to engineered transactions and the legal framework applicable to CDS. First, this Article creates a typology of the three primary strategies CDS counterparties use when engaging in engineered transactions. Relying on four case studies, this Article details the mechanisms underlying different engineering schemes, outlining how CDS counterparties are able to ensure the profitability of their CDS positions.

Second, this Article undertakes a careful analysis of the ex post and ex ante consequences of engineered transactions on three sets of actors: (i) issuers who participate in engineered transactions; (ii) CDS counterparties who have bought or sold protection on the issuer; and (iii) third parties that are unconnected to the engineered transaction and the CDS market. As a burgeoning strategy in the CDS market, the consequences of engineered CDS transactions on the market are under-analyzed, in part because of their newness, and in part because commentators summarily dismiss questions of the transactions' costs or benefits, depending on whether they are for or against the use of engineered CDS. ${ }^{18}$

16 See CFTC Press Release, supra note 12 (stating that manufactured credit events may constitute market manipulation); Testimony Concerning Credit Default Swaps Before the H. Comm. on Agric., 110th Cong. \ 23 (2008) (statement of Erik Sirri, Director, Division of Trading and Markets, SEC) ("[T] here is the risk that CDS are used for manipulative purposes.").

17 See discussion infra Part II.

18 See, e.g., Levine, supra note 12 (discussing the McClatchy-Chatham transaction as distinct from the Hovnanian trade because, unlike a bet where "CDS sellers bet that the credit wouldn't implode," the McClatchy-Chatham trade was a "bet that [McClatchy's] credit would implode, and 
This Article fills the gap in these conclusory discussions by balancing the ex post and ex ante effects of engineered transactions to assess whether the transactions' benefits outweigh their costs or vice versa. As this analysis demonstrates, engineered transactions result are net positive transactions for issuers and, at best, maintain the status quo of CDS as zero-sum transactions for CDS counterparties. However, with respect to third parties, engineered transactions impose negative externalities, including diminishing pricing efficiency, impairing market integrity, and imposing costs on non-CDS parties that are not internalized by the parties to an engineered transaction. Relatedly, owing to inherent informational asymmetries and the limited ability of CDS traders to force their counterparties to change their behavior, market discipline is not a feasible avenue through which to address engineered CDS transactions. ${ }^{19}$ The impotence of market discipline in limiting the costs associated with engineered CDS transactions further reiterates the need for a legal response to engineered CDS transactions.

Third, this Article examines whether any of the three sources of law applicable to CDS can effectively cabin the attendant consequences of engineered transactions. This analysis illuminates the shortcomings of statutory law, contract law, and private law in limiting the negative externalities arising from engineered CDS transactions. From a legal standpoint, engineered CDS transactions exist in a gray space beyond the reach of applicable sources of law that govern the CDS market. Neither federal anti-manipulation laws and regulations nor contract law limits engineered transactions. Legally, engineered transactions do not constitute market manipulation, despite their distortive effect on the market. ${ }^{20}$ Contractually, these transactions are not disallowed under the terms of the CDS contract and the covenant of good faith and fair dealing does not invalidate them. ${ }^{21}$ Additionally, this Article assesses ISDA's recently adopted amendments to the Master Agreement aimed at proscribing engineered transactions and finds that despite some positive attributes, it is too narrow to meaningfully respond to engineered transactions.

The costs of engineered transactions coupled with the limitations of the existing legal framework render the market unprotected from the harm that

\footnotetext{
then it didn't').

19 See infra Section III.C.

20 See infra Section IV.A. A quick note about the scope of this Article. The definition of market manipulation is beyond the scope of this Article and the absence of a definition ought not to distract from the Article's claims and analysis. Specifically, the Article assesses two separate things-(i) whether engineered transactions distort the markets and (ii) whether engineered transactions are legal, including if these transactions run afoul of anti-manipulation laws. In answering the questions of distortion and legality, it is therefore unnecessary for the Article to get into the debate regarding how to define market manipulation. Rather, the Article considers objective, economic factors to assess questions of distortion and the anti-manipulation legal framework to analyze issues of legality.

21 See infra Section IV.B.
} 
results from engineered CDS. Thus, this Article puts forward three proposals to respond to engineered transactions. First, it suggests an expansion of ISDA's amendments to make it more broadly applicable to all forms of engineered transactions. Second, it recommends regulatory interventions to impose good faith obligations on CDS market intermediaries, thereby reestablishing the duty of good faith and fair dealing in the CDS contract. Third, it proposes expanding the definition of price artificiality under antimanipulation laws to include legitimate but distortive trading strategies that negatively impact the market's price discovery process.

This Article proceeds in five Parts. Part I describes how CDS function, identifies participants within the CDS market, and examines the role of ISDA in the market's operation. Part II creates a typology of engineered CDS transactions and, with the aid of market examples, explains the varied ways in which CDS traders can exploit CDS contracts to guarantee the profitability of their investments. Part III examines the ex post and ex ante consequences of engineered CDS transactions on issuers, CDS counterparties, and third parties. Further, Part III assesses whether the market can force parties to internalize the externalities that accompany engineered transactions. Part IV analyzes the application of relevant laws, regulations, and private rules to engineered CDS transactions to demonstrate that these standards do not extend to prohibit or limit the detrimental effects of engineered transactions. In response to the shortcomings of the existing framework, Part V explores pathways for reform that would close the gap and limit the occurrence and impact of engineered transactions.

\section{AN OVERVIEW OF CREDIT Default SWAPS}

At first blush, CDS may seem to be esoteric financial products. ${ }^{22}$ However, at its foundation, a CDS is an insurance-like financial contract that enables parties to tailor their exposure to credit risk. ${ }^{23}$ Despite being

22 In this Article, CDS is used to refer to both the singular and plural forms.

23 Credit risk is the risk that a borrower may not be able to repay their debt and thus default on its outstanding obligations. GEORGE CHACKO ET AL., CREDIT DERIVATIVES: A PRIMER ON CREDIT Risk, Modeling, AND InStRuments 3-4 (2016). Credit risk is present whenever one party extends credit to another party. A CDS allows parties to transfer credit risk by providing "insurance" in the event of default. See Gina-Gail S. Fletcher, Hazardous Hedging: The (Unacknowledged) Risks of Hedging with Credit Derivatives, 33 REV. BANKING \& Fin. L. 813, 816 n.1 (2013-2014). Although the insurance analogy is useful, it is incomplete, as discussed infra, because there is no requirement that the protection seller have an insurable interest in the referenced debt obligation. See Eric A. Posner \& E. Glen Weyl, An FDA for Financial Innovation: Applying the Insurable Interest Doctrine to Twenty-First-Century Financial Markets, 107 Nw. U. L. REV. 1307, 1321-22 (2013) (discussing the insurable interest requirement for insurance products that is absent in financial products, like CDS); see also Lynn A. Stout, Why the Law Hates Speculators: Regulation and Private Ordering in the Market for OTC Derivatives, 48 DUKE L.J. 701, 721 (1999) (discussing the insurable interest requirement at common law and that its absence in derivatives results in these instruments being gambling contracts that ought to be illegal). 
described as "financial weapons of mass destruction" 24 and decried as innovations with little to no social utility, ${ }^{25} \mathrm{CDS}$ play an important and useful role in the financial markets. The advent and growth of CDS has revolutionized the credit market, enabling better and easier transfer of credit risk among parties, which in turn enhances market liquidity and enhances issuers' access to credit. ${ }^{26}$ Since the execution of the first CDS transaction in 1994, the CDS market has grown exponentially and, prior to the 2008 financial crisis, was one of the largest markets in the world. ${ }^{27}$ Today, the CDS market has shrunk in size, but its role is no less important. Engineered CDS transactions, however, undermine the utility of the CDS markets, providing another basis on which the instruments' utility may be called into question.

Part I lays the groundwork for understanding CDS and the CDS market. First, it explains the mechanics underlying CDS, including how payments are triggered and the incentives that these transactions create among counterparties. Next, Part I describes the CDS markets, highlighting the major players in the market, as well as the benefits and drawbacks of CDS. Lastly, Part I specifically discusses the role of ISDA in the CDS markets as the sole source of private rules for CDS market participants.

\section{A. A Primer on $C D S$}

A CDS is a type of credit derivative ${ }^{28}$ in which one party (the "protection seller") agrees to compensate the other party (the "protection buyer") in the event the debt issuer (the "reference entity" or "underlying")

24 Letter from Warren E. Buffett, Chairman of the Bd., Berkshire Hathaway Inc., to Shareholders of Berkshire Hathaway Inc. 13-15 (Feb. 21, 2003), http://www.berkshirehathaway.com/letters/2002pdf.pdf (warning of the dangers of credit derivatives, and calling derivatives "time bombs" and "financial weapons of mass destruction").

25 See Press Release, The Vatican, “'Oeconomicae et Pecuniariae Quaestiones'. Considerations for an Ethical Discernment Regarding Some Aspects of the Present EconomicFinancial System" of the Congregation for the Doctrine of the Faith and the Dicastery for Promoting Integral Human Development (May 17, 2018), http://press.vatican.va/content/salastampa/en/bollettino/pubblico/2018/05/17/180517a.html (stating that the spread of CDS is "unacceptable from the ethical point of view").

26 See Frank Partnoy \& David A. Skeel, Jr., The Promise and Perils of Credit Derivatives, 75 U. CIN. L. REV. 1019, 1022-27 (2007) (discussing the major benefits associated with CDS).

27 Robert Smith, Credit Default Swaps: A \$10tn Market that Leaves Few Happy, FIN. TIMES (July 24, 2017), https://www.ft.com/content/10af64da-7075-11e7-93ff-99f383b09ff9. Immediately preceding the onset of the financial crisis in 2008, the CDS market had an outstanding notional value of almost $\$ 60$ trillion. Since the crisis, the market has shrunk considerably, with the outstanding value in 2016 approximating $\$ 10$ trillion. $I d$.

28 A derivative is a financial instrument whose value is derived from the value of an underlying reference asset — such as a security, commodity, interest rate, etc. - or an external event. A credit derivative is a financial contract for which the payout depends on the credit performance of a corporation or sovereign (i.e., whether the reference entity defaults on its debts). See Fletcher, supra note 23, at 824-32 (discussing the different forms of credit derivatives). 
experiences a "credit event," such as a default or a credit rating downgrade. ${ }^{29}$ In exchange, the protection buyer pays periodic premiums to the protection seller. ${ }^{30}$ If a credit event occurs, the protection buyer is entitled to a payoff. ${ }^{31}$ On the other hand, if a credit event does not occur during the contractual period, the protection seller profits on the premiums collected during the life of the contract.

Credit events are contractually defined performance triggers that determine whether a protection buyer is entitled to compensation. ${ }^{32}$ Deciding whether a credit event has occurred is the responsibility of the Credit Derivatives Determinations Committee. ${ }^{33}$ Each Determinations Committee is comprised of fifteen members, ten of whom are major CDS dealers. ${ }^{34}$ Its decisions must be made by a supermajority and are binding on market participants. ${ }^{35}$ Any eligible CDS market participant may request that the Determinations Committee resolve whether there has been a triggering credit event. ${ }^{36}$ If the Determinations Committee decides that there has been a credit event, the Committee holds a centralized auction to establish the settlement price of the underlying asset. ${ }^{37}$ The settlement price is established by reference to the lowest-priced bond trading on the market (i.e. the cheapest to deliver). ${ }^{38}$ Once a settlement price has been set, the CDS protection buyer

29 Robert S. Bloink, Does the Dodd-Frank Wall Street Reform Act Rein in Credit Default Swaps? An EU Comparative Analysis, 89 NEB. L. REV. 587, 594 (2011) (“A . . credit default swap (CDS) is a bilateral contract under which a protection seller promises to make good on the protection buyer's losses in the event that the entity ... that issued the CDS's underlying bond defaults on its debt obligations prior to the maturity of the CDS.").

30 PRACTICAL LAW FIN., supra note 6, at 2. ("In return for the credit protection seller assuming this credit risk, the credit protection buyer makes periodic premium payments over the term of the swap to the credit protection seller.").

31 "Credit events" are defined by the ISDA to include "bankruptcy, failure to pay, obligation acceleration, obligation default, repudiation/moratorium, or restructuring." INT'L SWAPS \& DERIVATIVES ASS'N, 2003 ISDA CREDIT DERIVATIVES DEFINITIONS 30 (2003), http://cbs.db.com/new/docs/2003_ISDA_Credit_Derivatives_Definitions.pdf.

32 Id.

33 INT'L SWAPS \& DERIVATIVES AsS'N, THE ISDA CREDIT DERIVATIVES DETERMINATIONS COMMitTEES 1 (2012), https://www.isda.org/a/CHDDE/agm-2012-dc-anniversary-appendix043012.pdf.

34 Id. at 2. See infra Section I.B for a discussion of CDS dealers.

35 INT'L SWAPS \& DERIVATIVES ASS'N, supra note 33, at 3,8.

36 See id.

37 Id. at 1.

38 Fabien Carruzzo et al., iHeart and Other Unconventional CDS Credit Events, WESTLAW 1, 2 (May 17, 2017) (explaining how when a credit event occurs for the reference entity, "a credit protection seller must pay to its protection buyer an amount equal to the percentage in decline in the value, compared to par, of the 'cheapest to deliver' qualifying debt obligation of the reference entity...."). The mechanics underlying how the Determination Committee establishes the cheapest-to-deliver bond are beyond the scope of this Article. In a nutshell, the cheapest-to-deliver bond is the lowest-valued bond, covered by the CDS that is presented at the auction for purchase. By valuing the payoff according to the lowest-valued bond, the Determinations Committee ensures that all protection buyers receive the same payoff value (i.e., par minus the cheapest-to-deliver bond), by establishing the lowest possible price the market is willing to pay for the defaulted 
is entitled to a payout valued at the difference between the par value of the bond (the face value) and the auction-established settlement price of the bond. ${ }^{39}$

An example may be helpful to further explain the mechanics and payoff valuation of CDS. Assume that Widgets Inc. ("Widgets") issues a $\$ 40$ million bond that matures in five years. ${ }^{40}$ An investor, Ingrid, purchases $\$ 1$ million of Widgets' bonds at par value. ${ }^{41}$ The bond exposes Ingrid to credit risk, that is, the risk that Widgets may not be able to repay its debt in five years. To protect herself against Widgets' credit risk, Ingrid, the protection buyer, may purchase a CDS on the $\$ 1$ million Widgets bond, which transfers the risk of loss from Widgets' default from Ingrid to her CDS counterpartyState Bank of Portlandia ("BP"), the protection seller. Per the CDS agreement, Ingrid makes contractually specified periodic premium payments to her CDS counterparty, BP.

The CDS protects Ingrid from the decline in value of Widgets' bonds if Widgets is unable to repay its debt. Meanwhile, BP receives a steady stream of payments during the life of the CDS contract, which will be its profit if Widgets does not default. If Widgets defaults, and the ISDA Determinations Committee decides that the default constitutes a credit event, BP owes Ingrid the difference between the par value of Widgets' bonds and the cheapest-todeliver bond established through an ISDA auction. Thus, if post-default, the cheapest Widgets bonds trade at ten cents on the dollar, BP must compensate Ingrid $\$ 900,000$ - the difference between par value $(\$ 1,000,000)$ and the price of the cheapest-to-deliver bond $(\$ 100,000)$.

When one considers the Widgets example, it becomes evident that both $\mathrm{BP}$ and Ingrid have competing preferences and interests with respect to Widgets' future solvency. On the one hand, BP would prefer for Widgets to remain solvent, as this would allow it to profit on the premiums it charged

issuer's bond. For more details on the process and benefits of the Determinations Committee's auction process, see Short-Squeeze Risks Loom Again in CDS Markets, JONES DAY (Jan. 11, 2019), https://www.jonesday.com/Short-Squeeze-Risks-Loom-Again-in-CDS-Markets-01-11-2019.

39 InT'L ORg. OF SEC. COMM'NS, The Credit Default Swap Market 3 (2012), https://www.iosco.org/library/pubdocs/pdf/IOSCOPD385.pdf (“'I]f 'cash settlement' is the agreed settlement method, the seller must pay to the buyer the difference between the notional contract value and the market value of the bonds.").

40 A bond is a type of security in which an issuer, such as a corporation, municipality, or sovereign, borrows money for a defined period from investors, known as bondholders. Bondholders are creditors of the issuer and may be entitled to receive periodic interest payments until the bond matures.

41 Par value is the face value of the bonds. It is not necessarily what the investor pays for the bonds. For example, a bond may have a par value of $\$ 100$ but it is being sold below par at $\$ 97$. In this case, the original purchase price of the bond is below par. However, in determining the payout for a CDS, it is the par value that is used in determining the payments owed if there is a credit event. See Lionel Pavey, Credit Default Swap; What Is It - Good or Bad?, TREASURYXL (Mar. 26, 2018), https://www.treasuryxl.com/news-articles/credit-default-swap-good-bad ("[W]hen the CDS market started, it was seen as a product to protect bond holders and, in the event of a default, the CDS buyer could deliver the agreed reference obligation and receive its par value."). 
Ingrid for credit protection. BP's obligation to make Ingrid whole in the event of Widgets' defaults reduces the profitability of the CDS transaction for BP. Further, if BP did not charge enough for the credit protection, it may experience a financial loss if the premiums it collected are less than the amount owed to Ingrid.

On the other hand, Ingrid may prefer that Widgets defaults but the reasons for this are less obvious at first glance. To start, in the above hypothetical, Ingrid has hedged her exposure to Widgets' credit risk and, with all things being equal, she ought to be agnostic as to Widgets' default. However, as a bondholder that has hedged her credit exposure to Widget, Ingrid becomes an "empty creditor" that may stand to profit more from Widgets' default than from its continued solvency. ${ }^{42}$ In purchasing a $\$ 1$ million bond from Widgets that matures in five years, Ingrid is entitled to a repayment of her $\$ 1$ million investment plus any periodic interest payments due over the life of the bond. If Widgets later faces financial distress, it likely will ask its bondholders, like Ingrid, to restructure its debt, which may involve a reduction on the outstanding debt, an extension of the payment date, or some combination thereof. Whereas restructuring the debt may result in losses for Ingrid, she could recoup her investment (less transaction costs) if Widgets defaults and her counterparty, BP, compensates her per their CDS. Thus, as an empty creditor, Ingrid may be unwilling to work with Widgets to restructure its debt and would, instead, prefer that Widgets defaults. ${ }^{43}$

Ingrid's preference for Widgets' default is more pronounced when the above example is modified such that she has no pre-existing exposure to Widgets' credit risk through a bond. In this scenario, Ingrid purchases "naked" credit protection on Widgets' debt as a speculator and, therefore, she is no longer agnostic as to whether or not Widgets defaults. Rather, the only way in which she profits on the CDS transaction is if Widgets defaults. As a speculator, Ingrid pays her periodic premiums just as she would as a hedger, but she receives no return on the investment if Widgets remains solvent during the life of the CDS. Thus, Ingrid is incentivized to encourage Widgets' default to ensure the profitability of her CDS.

The preferences that Ingrid, the protection buyer, and BP, the protection seller, face - to encourage or prevent Widgets' default, respectively - arise from the innate structure of the CDS. Specifically, the ability to use CDS to place naked bets on the likelihood of default of the underlying issuer creates incentives for CDS counterparties to distort the utility of CDS, which can

42 Henry T.C. Hu \& Bernard Black, Equity and Debt Decoupling and Empty Voting II: Importance and Extensions, 156 U. PA. L. REV. 625, 732 (2008) (“[A]n empty creditor may prefer to force the company into bankruptcy, rather than agree to a restructuring, because the bankruptcy filing will trigger a contractual payoff on its swap position.").

43 For a fuller discussion and analysis of the empty creditor problem, see Patrick Bolton \& Martin Oehmke, Credit Default Swaps and the Empty Creditor Problem, 24 REV. FIN. STUD. 2617 (2011). 
disrupt the CDS market in significant ways.

\section{B. The CDS Market}

In the years leading up to the 2008 financial crisis, CDS transformed from obscure, high-finance products into popular, widely-traded financial instruments. In 2007, at the peak of the CDS market, the outstanding notional value of CDS exceeded $\$ 60$ trillion. ${ }^{44}$ Post-crisis, the CDS market has shrunk considerably, with recent reports estimating the outstanding notional value of CDS contracts at approximately $\$ 10$ trillion. ${ }^{45}$ The primary buyers and sellers of CDS are known as "swap dealers" and include many of the largest financial institutions globally, such as J.P. Morgan, Bank of America, Credit Suisse, and UBS, among others. ${ }^{46}$ The top fourteen CDS dealers are counterparties to ninety percent of the outstanding notional value of CDS.

Swap dealers act as market makers and are willing to take the opposite side of a CDS trade with another dealer or a non-dealer. ${ }^{47}$ The CFTC and the SEC share regulatory authority over swap dealers, requiring them to register with the respective agency in order to participate in the CDS market. ${ }^{48} \mathrm{In}$ registering, swap dealers are subject to extensive regulations as a requirement of participating in the CDS market. They must report trades, comply with capital and margin requirements, and establish risk management protocols to monitor credit, liquidity, legal, and operational risks. ${ }^{49}$ Swap dealers are intermediaries in the CDS market, profiting mostly on facilitating the transaction and offsetting their exposure whenever possible. In contrast, non-dealers trade in CDS to hedge their credit exposure

44 Iñaki Aldasoro \& Torsten Ehlers, The Credit Default Swap Market: What a Difference a Decade Makes, 2018 BANK FOR INT'L SETTLEMENTS Q. REV. 1, 2 (June 2018) (“In terms of notional amounts outstanding, the [global CDS] market has seen a continuous decline after peaking at roughly $\$ 61.2$ trillion at end-2007 ...."). With CDS, "notional value" refers to the "maximum potential counterparty exposure of the protection seller to the protection buyer." Id. at 3 .

45 See Smith, supra note 27 ; id. at 3 fig. 1.

46 The complete list of top CDS dealers includes: Bank of America, Barclays, BNP Paribas, Citigroup, Credit Suisse, Deutsche Bank, Goldman Sachs, HSBC, JPMorgan Chase, Morgan Stanley, Royal Bank of Scotland, Société Générale, UBS, and Wells Fargo. DAVID MENGLE, INT'L SWAPS \& DERIVATIVES ASS'N, CONCENTRATION OF OTC DERIVATIVES AMONG MAJOR DEALERS 1, 2 n.2 (2010), https://www.isda.org/a/VSiDE/concentrationrn-4-10.pdf.

47 INT'L ORG. OF SEC. COMM'NS, supra note 39, at 18.

48 See 17 C.F.R. § 3.2(c)(3) (2018). Three caveats must be noted here. First, registration is required for an entity or individual to participate in any segment of the swaps market, not only CDS. However, in light of the focus of the Article, the emphasis will be on CDS. Second, in referring generally to "swaps," the Article is referring both to swaps (which fall under the purview of the CFTC) and security-based swaps (which fall under the purview of the SEC). Third, the Commissions also have authority over a class of actors named "major swap participants." The Article is not including them in the discussion above because (i) no entity is currently registered as a major swap participant and (ii) the rules applicable to major swap participants largely mirror those related to swap dealers.

49 See Capital Requirements of Swap Dealers and Major Swap Participants, 81 Fed. Reg. 91,252 (Dec. 16, 2016) (codified at 17 C.F.R. pts. 1, 23, 140). 
or, alternately, to gain exposure to credit risk. ${ }^{50}$ Non-dealers include smaller banks, other financial institutions, institutional investors (such as pension funds and mutual funds), and hedge funds, among others. ${ }^{51}$

CDS are versatile financial instruments that can be used either to hedge against or speculate on credit risk. When used to hedge, a CDS counterparty has preexisting exposure to the reference entity's (i.e., the issuer) credit risk through a bond or loan, and the CDS provides insurance against this risk. Prior to the introduction of CDS, a bond investor or lender would have to sell all or some of its risk exposure to minimize the credit risk of the reference entity. However, an investor may only want to mitigate some of the risk or may only want to do so for a specified period. Furthermore, selling and repurchasing the debt would involve additional transaction costs that would increase the investor's costs and decrease the available capital for the markets. With CDS, a debt investor can protect against credit risk with fewer transaction costs and greater precision. Non-dealers, such as pension funds and mutual funds for example, typically utilize CDS to hedge their credit risk exposure, relying on the insurance-like features of CDS to manage their risk profile. $^{52}$ Thus, the malleability of CDS enables investors to customize their risk profile, such that they only bear credit risk linked to specific industries, for a certain time, or up to a specified level. ${ }^{53}$

CDS may also be used to speculate on an issuer's credit risk. Unlike hedgers that have prior credit risk exposure to the reference entity, speculators have no credit risk exposure prior to purchasing a CDS, thus making their CDS "naked." ${ }^{4}$ Naked CDS allow investors to gamble on the likelihood of default, and they have become the more prevalent use of CDS in the market. ${ }^{55}$ With naked CDS, traders can speculate on the ordinary course of business for its own account; or [e]ngages in any activity causing the person to be commonly known in the trade as a dealer or market maker in swaps"). See generally GIULIO Girardi, Craig Lewis \& Mila Getmansky, InTERCONNECTEDNESS IN THE CDS Market (2014), https://www.sec.gov/dera/staff-papers/white-papers/credit-defaul-swapsinterconnectivity-04-2014.pdf (discussing the increasing interconnectedness among dealers and non-dealers in the CDS market and its effect on overall market stability).

51 INT'L ORG. OF SEC. COMM'NS, supra note 39, at 6.

52 See M. Todd Henderson, Credit Derivatives Are Not 'Insurance,' 16 CoNN. INS. L.J. 1, 9 (2009) ("The participants in this market are large commercial banks, as risk sellers, and ... hedge funds [and] pension funds . . . as risk buyers. In this way, CDS contracts resemble other risk-sharing arrangements, like the syndication of credit or the sale of loans by banks.").

53 See Partnoy \& Skeel, supra note 26, at 1024 ("[CDS] can be combined with ... other derivatives to create almost any desired risk profile. If the lender wishes to bear a borrower's firmspecific default risk, but not risk related to [an industry], the lender could purchase derivatives that would compensate the lender in the event of an industry downturn ....").

54 Henderson, supra note 52, at 17.

55 See David McIlroy, The Regulatory Issues Raised by Credit Default Swaps, 11 J. BANKING REG. 303, 308 (2010) ("[I]n January 2009, [it was] estimated that as much as 80 per cent of the 
creditworthiness of debt issuers, without incurring the transaction costs to buy or sell the underlying debt. For example, suppose an investor believes that Widgets is likely to default on its upcoming bond payments. Without CDS, the investor would have to short Widgets' bonds, thereby incurring additional transaction costs and risks. ${ }^{56}$ With CDS, the investor can mimic a short sale by purchasing naked credit protection against Widgets' outstanding debt, which incurs lower transaction costs; if Widgets defaults, the investor will receive a payoff, and if it does not, she has lost the premium payments. ${ }^{57}$

Despite its shrinking size, the CDS market is nonetheless an important segment of the financial markets, and turmoil in the CDS market can have significant repercussions in the wider financial markets. CDS, particularly naked CDS, amplify the consequences of default, because the issuer's default results in losses not only for bondholders, but also for counterparties to CDS related to the issuer's debt. Given that the value of outstanding CDS on publicly-traded debt is many times higher than the value of the outstanding debt, an ill-timed default by a major issuer could have significant ripple effects throughout the markets. ${ }^{58}$ The impact of default is further magnified by the fact that most CDS transactions are highly leveraged, ${ }^{59}$ and, consequently, even small market changes may have a profound marketwide impact. ${ }^{60}$ Default by an issuer, therefore, may require credit protection sellers to make significant payoffs that may threaten the protection sellers' viability and financial stability. Additionally, CDS increase interconnections

CDS market is traded by companies that do not own the underlying debt."); see also DOMINIC O'Kane, Modelling Single-Name and Multi-Name Credit Derivatives 1 (2008) (explaining that in 2007, the amount of credit derivatives outstanding was estimated to be $\$ 45.46$ trillion, comparing to the bond market which was estimated to be $\$ 5.7$ trillion).

56 Additional transaction costs would include the costs to borrow the securities and fees for the sale and repurchase of the securities. Further, if the price of Widgets' bonds does not decrease, the investor will be forced to repurchase the securities at a higher price and, if there is a limited supply of the bonds, this also increases her risks.

57 See supra Section I.A (explaining through use of a hypothetical example how CDS may be used to speculate on the likelihood of default).

58 See The Role of Derivatives in the Financial Crisis: Hearing Before the Fin. Crisis Inquiry Comm'n, 111th Cong. 17-18 (2010) (statement of Michael Greenberger, Professor, University of Maryland School of Law) (describing the ripple effect that occurred during the 2008 financial crisis), http://fcic-static.law.stanford.edu/cdn_media/fcic-testimony/2010-0630-Greenberger.pdf; see also McIlroy, supra note 55, at 308 ("[I]n January 2009, Eric Dinallo estimated that as much as 80 per cent of the CDS market is traded by companies that do not own the underlying debt.").

59 "[A] transaction is leveraged when a counterparty does not commit capital to cover the full amount of its future obligation under the contract." Fletcher, supra note 23, at 895-96. For example, in entering into a CDS contract, the protection seller is not required to commit the full value of the CDS to demonstrate its ability to pay. Rather, the protection seller typically pledges a percentage of the value of the contract as collateral, but otherwise the transaction is highly leveraged.

60 See Yesha Yadav, The Case for a Market in Debt Governance, 67 VAND. L. REV. 771, 792 (2014) (explaining that the amount and quality of the collateral that protection buyers demand from protection sellers depends on the risk presented by the entity that originally borrowed from the lender, and not the full value of the CDS itself). 
among large, systemically important financial institutions. ${ }^{61}$ The top fourteen CDS dealers enter into over sixty percent of CDS transactions. ${ }^{62}$ The concentrated nature of the CDS market creates a web of contractual relationships among large financial institutions that increase the risk that CDS losses at one institution could trigger cascading losses throughout the financial markets. ${ }^{63}$ Thus, the stability of the CDS markets is essential to the proper functioning of the broader financial markets. Attempts to distort or otherwise undermine the CDS markets, therefore, ought to be addressed promptly so as to minimize the potential far-reaching consequences of such conduct.

\section{The Role of ISDA}

Key to the development and growth of the CDS market was standardization of the CDS contract, an effort spearheaded by ISDA. ${ }^{64}$ Founded in 1985, ISDA is a global financial trade association that was established to standardize documentation for the derivatives markets and reduce the significant transaction costs that accompanied derivatives trades. ${ }^{65}$ To this end, ISDA created the Master Agreement, which is the foundational contract for all CDS trades. ${ }^{66}$ The Master Agreement delineates the obligations of parties, defines what constitutes a credit event, and details procedures for early termination and transfer of CDS contracts, among other things. ${ }^{67}$ Parties may modify default provisions in the Master Agreement by including their amendments in the "Schedule." 68 Together, the Master Agreement and the Schedule form the contractual basis for all CDS

61 See generally StÉPhane CRÉPEy, Monique JEANBlanc \& BeHnaZ Zargari, COUNTERPARTY RISK ON A CDS IN A MARKOV CHAIN COPULA MODEL WITH JOINT DEFAULTS (2009).

62 INT'L ORG. OF SEC. COMM'NS, supra note 39, at 6.

63 Johnson, supra note 5, at 213.

64 See Romain G. RANCIERE, InT'L MONETARY Fund, CREDIT DERIVATIVES IN EMERGING MARKETS 4 (2002), https://econ-papers.upf.edu/papers/856.pdf ("The standardization of the legal documentation has been a driven [sic] force in the development of the credit derivatives market. Based on the 1999 Credit Derivatives Definitions issued by the International Swap and Derivatives Association (ISDA), the new ISDA confirmation form has turned default swaps into plain vanilla derivatives products ....").

65 Robert F. Schwartz, Risk Distribution in the Capital Markets: Credit Default Swaps, Insurance and a Theory of Demarcation, 12 FORDHAM J. CORP. \& FIN. L. 167, 178 (2007).

66 See Irene Spagna, Becoming the World's Biggest Market: OTC Derivatives Before the Global Financial Crisis of 2008, in GOVERNING THE WORLD's BIGGEST MARKET: THE POLITICS OF Derivatives Regulation AfTER THE 2008 CRisis 27, 41 (Eric Helleiner et al. eds., 2018) ("[The ISDA Master Agreement] provided industry-wide accepted definitions of key terms ... which could be used across a variety of transactions.").

67 See PRACTICAL LAW FIn., RESOURCE ID No. 1-386-3976, ISDA DOCUMENTS: OVERVIEW (US), Westlaw (last visited Mar. 15, 2019) (explaining the role of ISDA in the derivatives market).

68 Schwartz, supra note 65, at 178 ("If parties desire to modify any default provisions in the Master Agreement for their transaction, they may do so in an amending document called a 'Schedule."'). 
transactions between counterparties.

In standardizing the foundational documents for CDS trades, ISDA reduced transaction costs which, in turn, has fostered the expansion of the CDS markets. Notably, the creation of a private legal infrastructure to govern CDS raised questions regarding the legal validity of CDS contracts and the potential for uncertainty in judicial interpretation of contract terms, particularly across different jurisdictions and legal regimes. ${ }^{69}$ In furtherance of these goals, ISDA has sought and received assurances from over thirty countries that ISDA's provisions are enforceable as law. ${ }^{70}$ ISDA also plays a prominent role in litigation related to the interpretation of the Master Agreement, writing amicus briefs and issuing its own contract interpretation..$^{71}$

As the standard setter for the CDS market, ISDA intervenes when judicial or regulatory interpretation of the Master Agreement may result in ambiguity or disruptions to the CDS market. ${ }^{72}$ One prominent example involved questions as to whether Argentina's "voluntary debt exchange" on its outstanding bonds constituted a credit event under the Master Agreement. ${ }^{73}$ At the time, a mandatory debt exchange, known as an "Obligation Exchange" was deemed a credit event. ${ }^{74}$ But it was unclear whether the Argentine debt exchange, despite being labelled "voluntary," was in fact voluntary. ${ }^{75}$ Concerned about the potential far-reaching ramifications of the ambiguity, ISDA acted quickly and decisively. It removed "Obligation Exchanges" from the definition of a credit event and convened a group of experts to revise the credit event definitions in the Master Agreement. ${ }^{76}$

69 Geoffrey P. Miller \& Fabrizio CAFAgGi, The Governance and Regulation of INTERNATIONAL FINANCE 58-59 (2013).

70 Frank Partnoy, ISDA, NASD, CFMA, and SDNY: The Four Horsemen of Derivatives Regulation? 5-6 (Univ. of San Diego Sch. of Law Pub. Law \& Legal Theory, Working Paper No. $39,2002)$

71 See Amicus Briefs, INT'L SWAPS \& DERIVATIVES ASS'N, https://www.isda.org/1970/01/01/amicus-briefs (last visited Aug. 3, 2019) (“ISDA files amicus briefs . . . in court cases around the world that raise important policy issues that impact the overthe-counter derivatives market and market participants.").

72 Anna Gelpern, Domestic Bonds, Credit Derivatives, and the Next Transformation of Sovereign Debt, 83 CHI.-KENT L. REV. 147, 171 (2008) (describing ISDA as the "unofficial guardian" of the CDS market that intervenes when a court's interpretation of the Master Agreement may "unsettle market expectations").

73 See supra text accompanying notes 28-36; Eternity Glob. Master Fund Ltd. v. Morgan Guar. Trust Co., 375 F.3d 168, 177-78 (2d Cir. 2004). More specifically, per the Master Agreement a "Restructuring" constituted a credit event and included "Obligation Exchanges." At issue was whether the Argentine "voluntary debt exchange" was mandatory and, therefore, a credit event, or voluntary and, therefore, not. Id. at 180 .

74 Id.

75 Id. at 181.

76 See Stephen J. Choi \& G. Mitu Gulati, Contract as Statute, 104 Mich. L. REV. 1129, 1144 (2006). 
To address the essential question of whether a CDS reference entity has defaulted, ISDA established Determinations Committees to make binding decisions on whether a credit event has occurred. ${ }^{77}$ In forming the Determinations Committee, ISDA created a private, industry-led body to govern a key element of the Master Agreement, enhancing market certainty. ${ }^{78}$ Generally, ISDA and the Determinations Committee adopt a textualist approach to interpreting the Master Agreement, with little to no consideration of extraneous evidence or factors. ${ }^{79}$ In embracing a textualist and formalistic approach to the Master Agreement, ISDA aims to have courts and CDS parties rely exclusively on the contract text in interpreting related rights and obligations. ISDA's textualist interpretation of the Master Agreement focuses on the terms of the contract as written, with little regard for the negative effects that arise from strict application of the contract. ISDA's stance on the Greek debt crisis is an illustrative example in this regard. To determine whether Greece's proposed restructuring triggered CDS payments, ISDA narrowly and inflexibly interpreted the text of the Master Agreement to decide that Greece's restructuring was not a credit event legally, even though economically and practically the country was in default. ${ }^{80}$

Despite the importance of ISDA to the CDS markets, it is not subject to any regulatory oversight nor does it have authority over market participants. ${ }^{81}$ ISDA is not an administrative agency nor is it a quasigovernmental agency akin to the Financial Industry Regulatory Authority. Fundamentally, ISDA is a trade association, ${ }^{82}$ in which major dealers, its primary members, dominate the organization and exert considerable influence over its operation. ${ }^{83}$ After the 2008 crisis, the Dodd-Frank Act

77 INT'L ORG. OF SEC. COMM'NS, supra note 39, at 12.

78 See generally Anna Gelpern \& Mitu Gulati, CDS Zombies, 13 EuR. BuS. ORG. L. REV. 347 (2012) (discussing the establishment of Determinations Committees and their benefits for the CDS markets).

79 See generally id. (discussing ISDA's textualist approach to its interpretation of the Master Agreement, specifically in relation to the Greek debt crisis).

80 See Greek Sovereign Debt Q\&A (Update), INT'L SWAPS \& DERIVATIVES AsS'N (July 25, 2011),

https://www.isda.org/2011/07/25/greek-sovereign-debt-qa-update (stating that a voluntary debt exchange would not trigger a Credit Event).

81 See Kathryn Collard, Note, Advantages of a Co-Regulatory OTC Derivatives Regime, 46 GEO. J. INT'L L. 877, 979 (2015) (describing ISDA as a "private industry group" that is not formally involved in shaping the regulatory framework that governs the derivatives market).

82 See Mark J. Roe \& Stephen D. Adams, Restructuring Failed Financial Firms in Bankruptcy: Selling Lehman's Derivatives Portfolio, 32 YALE J. ON REG. 363, 398 n.102 (2015) ("ISDA . . . began as the major derivatives banks' trade association.").

83 ISDA has three membership classes: (i) primary members, which includes derivatives dealers; (ii) associate members, which includes professional service providers in the derivatives markets; and (iii) subscribers, which includes anyone not eligible for the first two membership classes. However, only primary members have voting rights and are eligible to serve as officers and directors of ISDA. INT'L SWAPS \& DERIVATIVES ASS'N, BY-LAWS 2 (Apr. 11, 2019), 
brought the derivative market, including the CDS market, within the regulatory ambit of the CFTC and the SEC. ${ }^{84}$ However, ISDA remains beyond the jurisdictional scope of either agency, while simultaneously maintaining significant influence within the CDS market. ${ }^{85}$ Further, ISDA has little authority to enforce its rules or punish members who fail to comply. ${ }^{86}$ Market adherence to the Master Agreement and any amendments thereto that ISDA adopts, for example, are entirely voluntary. ${ }^{87}$ Yet, because of its importance to the CDS market, market participants generally adhere to ISDA's best practices, trading rules, and interpretive guidance, thereby making it the de facto leader of the derivatives market. ${ }^{88}$

In sum, despite being separate from and unaccountable to the CDS regulatory framework, ISDA has considerable influence over the CDS market. By acting as a standard-setter for derivatives, ISDA has been pivotal to the growth of the CDS market. Nonetheless, the lack of accountability coupled with its private, member-focused interests are a cause for concern, particularly within the CDS market. As the CDS market continues to evolve, the question arises as to whether leaving the CDS market beholden to ISDA, under the control of large dealers, and beyond the scope of regulatory authority, is best for the market and market participants. This is true particularly in light of the development of engineered CDS transactions, which only received attention from ISDA after the CFTC publicly denounced the transactions.

II

ENGINEERED CREDIT DEFAULT SWAPS: TYPOLOGY AND MARKET EXAMPLES

Engineered CDS first appeared within the past six years ${ }^{89}$ since then,

https://www.isda.org/a/cDOEE/ISDA-By-Laws-March-14-2018.pdf.

84 Wall Street Transparency and Accountability Act of 2010, 15 U.S.C. $\S \S 8301-8344$ (2012).

85 See John Biggins, 'Targeted Touchdown' and 'Partial Liftoff': Post-Crisis Dispute Resolution in the OTC Derivatives Markets and the Challenges for ISDA, 13 GERMAN L.J. 1297, 1311-12 (2012) (stating that in the wake of the global financial crisis, ISDA has enmeshed itself in the regulatory process, working alongside regulators as they establish central clearing and exchange of derivatives).

86 See Johnson, supra note 5, at 231.

87 See, e.g., U.S. GOV'T ACCOUNTABILITY OfFICE, GAO-07-716, CREDIT Derivatives: CONFIRMATION BACKLOGS INCREASED DEALERS' OPERATIONAL Risks, BUT Were SUCCESSFUlly ADDRESSED AFTER JOINT REgulatory ACTION 25 (2007), http://www.gao.gov/new.items/d07716.pdf (describing adherence to ISDA protocols as "voluntary").

88 See A. Claire Cutler, The Judicialization of Private Transnational Power and Authority, 25 IND. J. GLOBAL LEGAL STUD. 61, 80-81 (2015) (explaining how ISDA's impact on the derivatives market is reflected by "the sheer volume of" market participants who use the association's standardized agreements); Andrew Verstein, Ex Tempore Contracting, 55 WM. \& MARY L. REV. $1869,1909-10$ (2014) ("Preference for ISDA documentation is partially a result of strong network externalities in the form of comprehensibility and fungibility in the eyes of other market participants.").

89 Practical Law Fin. ET AL., Resource ID No. W-014-1708, Understanding CRedit 
the schemes have become bolder, more creative, and more concerning. ${ }^{90}$ This Article defines an engineered CDS transaction as one in which a CDS counterparty (or a group working together) takes affirmative steps to guarantee that its CDS position is profitable. That is to say, if the counterparty is a protection buyer, it ensures that the CDS payoff is triggered; if it is a protection seller, it ensures that the CDS payoff is not triggered. Thus, the CDS counterparty uses its resources to tilt the outcome of the CDS to favor its position and increase the profitability of the contract. Notably, because of the short-term horizon for engineered CDS transactions, they are most profitable with financially distressed or near-distressed issuers.

Part II examines the phenomenon of engineered CDS transactions. It creates a typology to classify the strategies that counterparties employ to guarantee their preferred CDS outcome and, with the aid of market examples, describes the mechanics underlying these transactions. This Article classifies engineered transactions into three categories: (i) manufacturing default - CDS protection buyer incentivizing the issuer to voluntarily default on its outstanding debt; (ii) avoiding default - CDS protection seller providing a loan to temporarily forestall the issuer's default; and (iii) negating default - CDS protection seller restructuring the debt of the issuer to eliminate future possibility of default. Each is discussed in greater detail below.

\section{A. Manufacturing Default: The Cases of Codere \& Hovnanian}

The most controversial strategy CDS traders use to engineer CDS outcomes is manufactured default. In this scenario, the CDS protection buyer offers the issuer financing terms more favorable than the issuer could have received from the markets. In exchange, the issuer agrees to default on an outstanding debt, thereby triggering a credit event under the CDS agreement. With manufactured defaults, the issuer's default is voluntary - that is to say, in the absence of the CDS protection buyer's offer of financing, the issuer would meet its debt obligations. And, in some instances, the default is merely technical as the issuer eventually makes the required payments but does so late, thereby triggering a credit event. ${ }^{91}$ Thus, otherwise solvent issuers

Default Swaps (CDS): OpPORTUNistic Strategies, Westlaw (last visited Mar. 15, 2019) ("Engineered defaults... have been around for some time now - at least since Codere in 2013 ....").

90 See Charles W. Murdock, Credit Default Swaps: Dubious Instruments, 3 HARV. Bus. L. REV. 133, 134-36 (2013) (citing, among other factors, the unique nature of CDS transactions in impeding proper CDS pricing, JP Morgan's \$2 billion loss in trading, and a lack of due diligence in the banking industry as strengthening his notion of a "faulty rationale of credit default swaps").

91 Under the ISDA Master Agreement, payments received after the thirty-day grace period are deemed late, thereby putting the issuer in default. See ISDA, 2014 ISDA Credit Derivatives Definitions, Master Agreement Section 4.5 (defining a failure to pay with reference to the expiration of a "Grace Period" as defined in Section 1.45, if no Grace Period is specified in the contract, as thirty calendar days). 
consciously decide not to pay their debt obligations - manufacturing default - as a condition of their financing agreement and for the benefit of the CDS protection buyer that supplies the financing.

Manufactured defaults are most feasible and profitable with distressed companies for two reasons. First, a distressed company likely has limited access to the credit markets and, therefore, would be willing to accept financing in exchange for default. Further, if its financial situation is extremely precarious, a default may not have much of an impact on its credit rating; the company would, therefore, have little to lose and much to gain in the form of financing that would be otherwise unavailable. Second, in the event of a credit event, CDS payouts are valued at the difference between the par value of the referenced bonds and the cheapest-to-deliver bonds. ${ }^{92}$ The bonds of a company facing financial distress are likely trading significantly below par value, thereby providing the CDS investor with an opportunity to profit in the event of a default. Again, if the profits from the issuer's default are larger than the cost of extending financing to the issuer to incentivize it to default, then it could be worthwhile for a CDS protection buyer to engage in this transaction..$^{93}$

To date, engineered CDS transactions that involve voluntary defaults have been the most controversial because to many, this strategy most closely resembles cheating. ${ }^{94}$ Two well-known examples of engineered CDS transactions, involving Codere and Hovnanian, relied on manufactured defaults to guarantee payoffs for protection buyers. The two examples are discussed together because (i) the protection buyer in each case was GSO Capital Partners, a subsidiary of Blackstone, thus there are striking similarities in the schemes; and (ii) when viewed in succession, one sees how the strategy evolved to capitalize on the idiosyncrasies and structure of the CDS market.

\section{Codere}

One of the first known manufactured default transactions involved Codere, a publicly traded Spanish firm that operates race tracks and betting

92 See InT'L ORG. Of SEC. COMM'NS, supra note 39, at 3; see also supra notes 40-42 and accompanying text.

93 See, e.g., Matt Levine, Blackstone Made Money on Credit-Default Swaps with This One Weird Trick, BlOOMBERG OPINION (Dec. 5, 2013, 5:47 PM), https://www.bloomberg.com/view/articles/2013-12-05/blackstone-made-money-on-creditdefault-swaps-with-this-one-weird-trick. Levine explains that in 2013, GSO extended a $\$ 100$ million loan with favorable terms to Codere, and in exchange, Codere would intentionally default on some of its loan obligations. Therefore, GSO made between eleven million and fourteen million euros from its CDS contracts. $I d$.

94 See Davide Scigliuzzo, CFTC Steps into Debate on Voluntary Defaults, REUTERS (Apr. 27, 2018, 12:43 PM), https://www.reuters.com/article/us-cftc/cftc-steps-into-debate-on-voluntarydefaults-idUSKBN1HY2FY (explaining that many have agreed with the CFTC statement that intentional defaults "could amount to market manipulation"). 
parlors. In 2013, Codere was experiencing financial difficulties, as it posted its sixth consecutive quarterly loss and was largely unable to access additional financing. ${ }^{95}$ GSO purchased credit protection on Codere debt, betting on the company's insolvency. However, rather than waiting to see if Codere would make its upcoming debt payment, GSO intervened. Specifically, GSO, along with other lenders, offered Codere a much-needed $\$ 100$ million loan on favorable terms, but with an important condition: If Codere was on time in making its next debt payment, it would be required to repay the $\$ 100$ million loan immediately, in full. ${ }^{96}$ Ultimately, Codere was two days late in making its debt payments, ${ }^{97}$ but the late payment constituted a credit event and triggered CDS payments to protection buyers, such as GSO Capital. The resulting payments to CDS protection buyers totaled $\$ 197$ million. ${ }^{98}$

\section{Hovnanian}

The Codere transaction was only the beginning of GSO's engineered CDS transactions. GSO's transaction with Hovnanian was more sophisticated and stirred up more controversy in the markets. In 2017, GSO purchased \$330 million worth of credit protection on Hovnanian, a U.S. residential real estate construction company. ${ }^{99}$ Hovnanian had experienced financial difficulties because of the 2008 housing crisis, but, unlike Codere, the company was not facing imminent bankruptcy. ${ }^{100}$ Indeed, although Hovnanian's bonds were junk rated, they were trading close to or at face

95 Stephanie Ruhle, Mary Childs \& Julie Miecamp, Blackstone Unit Wins in No-Lose Codere Trade: Corporate Finance, BLOOMBERG (Oct. 22, 2013, 10:02 AM), https://www.bloomberg.com/news/articles/2013-10-22/blackstone-unit-wins-in-no-lose-codere-

trade-corporate-finance (discussing the loan provided by GSO Capital Partners LP to Codere SA).

96 Id. ("GSO and Canyon Partners LLC then took over what the company said at the time was 100-million-euro revolving loan .....”); A Bondholder Finds a Sneaky Way to Trigger Insurance Against Default, ECONOMIST (May 3, 2018), https://www.economist.com/finance-andeconomics/2018/05/03/a-bondholder-finds-a-sneaky-way-to-trigger-insurance-against-default (highlighting the favorable terms of the loan, stating that Codere received a "cheap \$100m loan"). Notably, GSO was also a creditor of Codere but held "basis play[]" CDS, which paid more in the event of default than if the debt was held to maturity. Thus, despite being a creditor of Codere, GSO stood to gain more in the event of default. Dan Primack, Blackstone Responds to Jon Stewart, FORTUNE (Dec. 6, 2013), http://fortune.com/2013/12/05/blackstone-responds-to-jon-stewart.

97 Payments made after a thirty-day grace period are considered a credit event under the ISDA Master Agreement, so the ISDA Determinations Committee officially declared Codere's thirtytwo-day late payment qualified as a credit event. See ISDA, 2014 ISDA Credit Derivatives Definitions, supra note 91.

98 Ruhle et al., supra note 95 ("[T] he International Swaps \& Derivatives Association ruled that there was a failure-to-pay credit event, resulting in a $\$ 197$ million payment to holders of the swaps.").

99 Rennison, supra note 4 (stating that GSO accumulated \$330 million in credit on Hovnanian). 100 See Scurria, supra note 2 (noting that at the time GSO offered Hovnanian a very attractive financing package, Hovnanian was not in severe financial distress and had the funds to pay its debts). 
value, thereby indicating no market panic over the company's financial situation. ${ }^{101}$ GSO offered Hovnanian a loan on terms much more favorable than the company could have received from another lender in its current financial condition. ${ }^{102}$ And, as with Codere, the loan required that Hovnanian miss a specified upcoming debt payment. ${ }^{103}$ However, the GSO-Hovnanian transaction faced two potential obstacles because, although heavily indebted, Hovnanian was not financially distressed. First, a default would negatively impact Hovnanian's market reputation and credit rating, likely increasing the firm's future borrowing costs significantly. ${ }^{104}$ Second, with Hovnanian's bonds trading only slightly below par, GSO's CDS payout would be minimal because of the cheapest-to-deliver rule. ${ }^{105}$

To address these stumbling blocks, GSO included two material conditions in its Hovnanian deal. First, as part of the financing, Hovnanian's subsidiary bought Hovnanian bonds and Hovnanian defaulted only on the bonds held by its subsidiary, while making payments in full to all other bondholders. ${ }^{106}$ The default to the subsidiary would nonetheless constitute a credit event under the Master Agreement, but since it would not affect thirdparty bondholders, it was not expected to significantly harm Hovnanian's reputation in the markets. Second, the GSO financing included a twenty-twoyear bond with a five percent interest payment. ${ }^{107}$ Given that these terms were much better than Hovnanian's financial situation warranted, the bonds traded on the open market at less than half of its face value; ${ }^{108}$ as the lowest-

101 Matt Levine, Blackstone May Do Its Cleverest CDS Trade Again, BLOOMBERG OPINION (Nov. 17, 2017), https://www.bloomberg.com/opinion/articles/2017-11-17/blackstone-may-do-itscleverest-cds-trade-again (explaining that almost all Hovnanian's bonds were trading around par value, indicating no signs of "panic level[]," but had low-junk ratings).

102 See Sridhar Natarajan, GSO Beats Rival Funds to Hovnanian Deal in Credit Swaps Showdown, BLOOMBERG (Dec. 28, 2017, 4:38 PM), https://www.bloomberg.com/news/articles/2017-12-28/hovnanian-sides-with-gso-in-hedge-fundtiff-that-roiled-its-cds (explaining that Hovnanian's management and board reviewed several offers by financial firms to refinance their existing debt, but the company decided to accept GSO's offer due to its favorable terms).

103 See Rennison, supra note 4.

104 See Sudip Datta, Mai Iskandar-Datta \& Ajay Patel, Bank Monitoring and the Pricing of Corporate Debt, 51 J. FIN. ECON. 435, 437, 441 (1999) (explaining that the firm's "reputation is a valuable asset," which helps firms to borrow for less cost, and that "the yield spread for corporate debt is negatively related to the bond's rating").

105 See INT'L ORG. OF SEC. COMM'NS, supra note 39 and accompanying text; see also Levine, supra note 101 (explaining that Hovnanian's bonds were trading 92 and 108 cents on the dollar, therefore not leaving "much room to make money" by defaulting on its debt obligations).

106 Childs, supra note 2 (explaining that the deal between GSO and Hovnanian would not harm any real bondholder since Hovnanian's subsidiary was to buy bonds with its own money and then Hovnanian would default on those bonds).

107 Mary Childs, Solus Made Money from That CDS Litigation, BARRON's (June 20, 2018, 1:03 PM), https://www.barrons.com/articles/solus-made-money-from-that-cds-litigation-1529514208 ("In the exchange offer ... bond holders could tender for cash, for new notes yielding $13.5 \%$ and due in 2026 , or for $5 \%$ senior secured notes due in $2040 . ")$.

108 See id. ("[T]he 5\% notes due in 2040 have, by design, fallen since the exchange, to about 
priced bonds, these bonds would be used to determine CDS payouts if there was a credit event, per the cheapest-to-deliver rule. ${ }^{109}$ Thus, GSO ensured not only that its CDS would pay off, but it also ensured that its payoff would be substantial-all without violating the terms of the Master Agreement. Ultimately, GSO abandoned the transaction because of tremendous regulatory pressure. ${ }^{110}$ However, despite being abandoned, the GSOHovnanian transactions demonstrate the extent to which savvy players can engineer CDS transactions to the detriment of the markets and market participants, thereby undermining the efficiency and integrity of the CDS markets.

\section{B. Avoiding Default: The Case of RadioShack}

The traditional academic concern with respect to the distortion of CDS outcomes is the "empty creditor problem"- that is, the concern that CDS counterparties, specifically protection buyers, will force an issuer into bankruptcy to profit on their CDS positions. ${ }^{111}$ However, a CDS counterparty may engage in the reverse scheme: collaborating with the issuer to temporarily avoid default. A CDS protection seller can guarantee its preferred outcome by collaborating with the issuer to avoid an impending default until the credit protection it sold has expired.

Avoiding default works best with a financially distressed issuer because of the high price the counterparty can demand for insuring against the issuer's default, which increases the profitability of the transaction. To the extent the issuer remains solvent during the term of the contract, the protection seller profits on the premiums collected for guaranteeing the issuer's debts. However, if the issuer defaults, the protection seller faces potentially significant liabilities, which may not be adequately covered by the premiums it received. Thus, to avoid its obligations, the protection seller may extend a loan to the issuer to ensure it remains solvent for the duration of the protection seller's outstanding CDS contracts. Helping the issuer stay afloat can be profitable (or financially beneficial) for the protection seller if the protection seller either (i) earned more in premiums than would be needed to keep the issuer solvent, or (ii) faces greater potential liabilities

45 cents on the dollar ....”). Such terms would be remarkable even for the most financially stable firm, let alone Hovnanian that had a junk rating.

109 See Levine, supra note 101 (discussing how the cheapest-to-deliver rule plays out in a CDS auction).

110 In its first public statement on engineered CDS transactions, the CFTC opined that it viewed "[m]anufactured credit events" as market manipulation under the CEA. The Commission, however, did not explain the basis for it is opinion. CFTC Press Release, supra note 12.

111 Bolton \& Oehmke, supra note 43, at 2617. Bolton and Oehmke argue that CDS "alter[] the debtor-creditor relation ... as it partially or fully separates the creditor's control rights from his cash-flow rights." Id. This separation has raised concerns regarding empty creditors "push[ing] the debtor into inefficient bankruptcy or liquidation." Id. For a more in-depth discussion of the empty creditor problem, see supra Section I.A. 
from the issuer's default than would be covered by the premiums collected. In either instance, the CDS seller is incentivized to assist the issuer to avoid default, albeit temporarily, thereby guaranteeing the profitability (or minimizing the losses) on its CDS position.

RadioShack Corp. ("RadioShack") provides a salient example of this engineering strategy. RadioShack filed for bankruptcy in February 2015 after a sustained period of financial decline and rising debt. ${ }^{112}$ The company's insolvency was hardly surprising - the markets discounted RadioShack debt by eighty percent ${ }^{113}$ and RadioShack's third quarter filings in 2014 indicated that the company had approximately $\$ 60$ million of liquidity versus over $\$ 800$ million in debt. ${ }^{114}$ What was surprising was the timing of RadioShack's bankruptcy, which some allege was orchestrated to favor major CDS protection sellers. ${ }^{115}$ Beginning in 2013, RadioShack launched an aggressive turnaround effort that increased its debt-load but did little to stymie its decline. ${ }^{116}$ Market observers expected the company to declare bankruptcy in late 2014, ahead of the holiday shopping season; the CDS market reflected these expectations as protection on RadioShack debt

112 See Chris Isidore \& Katie Lobosco, RadioShack Declares Bankruptcy, CNN Bus. (Feb. 5, 2015, 8:39 PM), https://money.cnn.com/2015/02/05/news/companies/radioshack-bankruptcy (“It's been a long, slow decline for RadioShack. Losses have been mounting, and in its latest quarter sales plunged 16\% from a year ago. Cash-strapped, RadioShack found itself saddled with more than 5,000 stores at the beginning of last year, many of which it couldn't afford to keep open."). This was the first of RadioShack's bankruptcies; the second occurred in 2017 and is not relevant here. See Mike Snider, RadioShack Closing 187 Stores in Latest Bankruptcy Filing, USA TODAY (Mar. 9, 2017, 11:55 PM), https://www.usatoday.com/story/money/business/2017/03/09/radioshackfiles-bankruptcy-second-time/98943636 (reporting on RadioShack's 2017 bankruptcy filing).

113 RadioShack debt was trading at twenty cents on the dollar; for example, $\$ 10$ million of debt was worth \$2 million. See Stephen B. Selbst, RadioShack Dissected: The Decline, Fall and Possible Rebirth, ABFJoURNAL (Mar. 2016), https://www.abfjournal.com/\%3Fpost_type\%3Darticles\%26p\%3D45905 ("RadioShack could have sold its assets and liquidated in early 2014, which would have yielded a payout to unsecured creditors of approximately 20 cents on the dollar."); see also Rachelle Kakouris, Distressed Debt: RadioShack, Salus Capital Spar over Alleged Leveraged Loan Covenant Breach, FORBES (Dec. 2, 2014, 12:24 PM), https://www.forbes.com/sites/spleverage/2014/12/02/radioshack-salus-capitalspar-over-alleged-leveraged-loan-covenant-breach/\#8072738434f3 ("[F]ive-year CDS ... was roughly $3 \%$ wider this morning, at $65.5 / 68$ points upfront .... That's a highly distressed context for the contracts and represents about a $\$ 200,000$ extra upfront payment, at approximately $\$ 6.7$ million at the midpoint, in addition to the $\$ 500,000$ annual payment, to protect $\$ 10$ million of RadioShack bonds.").

114 Kakouris, supra note 113.

115 See Peg Brickley, Creditors Ask for Probe into Missed Chances to Save RadioShack, WALL ST. J. (Feb. 17, 2015), https://www.wsj.com/articles/creditors-ask-for-probe-into-missed-chancesto-save-radioshack-1424211428 (describing how unsecured bondholders sought a probe into whether RadioShack declared bankruptcy for the benefit of top-ranking lenders).

116 See Jonathan Schwarzberg, RadioShack Lines Up \$285 Million in Bankruptcy Financing, REUTERS (Feb. 6, 2015), https://www.reuters.com/article/us-radioshack-dipidUSKBN0LA1TB20150206 (explaining that in December 2013, RadioShack acquired $\$ 835$ million in debt from various creditors; however, it had to file for Chapter 11 bankruptcy in February 2015). 
in late 2014 traded significantly below par. ${ }^{117}$ Indeed, RadioShack was all but locked out of the credit markets-lenders and investors saw the proverbial writing on the wall and were unwilling to extend additional credit to the distressed company. ${ }^{118}$

Yet, there was another consideration at play-namely, the upcoming December 20, 2014 expiration on RadioShack-referenced CDS. ${ }^{119}$ Credit protection on RadioShack's indebtedness was quite expensive, thereby allowing CDS protection sellers to charge substantial premiums, which they would only be able to keep if RadioShack did not default. ${ }^{120}$ In October 2014, RadioShack's primary creditor, Standard General, led a consortium of hedge funds to extend a last-minute lifeline in the form of a $\$ 120$ million loan. ${ }^{121}$ Although unconfirmed, it has been strongly suggested that the hedge funds participating in the last-minute loan to RadioShack were protection sellers of RadioShack CDS. ${ }^{122}$ On the one hand, a favorable view of the loan is that it granted RadioShack another opportunity to turn its fortunes around. On the other hand, a cynical view is that it was a short-term loan that did not represent an investment in the future of the company; rather, it was a ploy to delay the company's inevitable bankruptcy for the benefit of CDS protection sellers.

Some CDS market participants shared the latter viewpoint and anonymously petitioned the ISDA Determinations Committee to decide whether the loan constituted a credit event under the ISDA Master Agreement. ${ }^{123}$ They argued that RadioShack's CDS would have been triggered but for the last-minute loan. The petition claimed that the loan was

117 See Kakouris, supra note 113.

118 Selbst, supra note 113 ("Few investors or lenders in the retail industry could have been surprised when RadioShack sought Chapter 11 protection in February 2015. . . The combination of reduced vendor credit and liquidity and declining sales led RadioShack to file for Chapter 11 on February 5, 2015.").

119 Kakouris, supra note 113.

120 Id.

121 Mike Kentz, CDS Allegations Surround RadioShack, REUTERS (Dec. 15, 2014, 9:25 AM), https://www.reuters.com/article/radioshack-cds/cds-allegations-surround-radioshackidUSL1N0TZ0V720141215.

122 See In re RadioShack Corp., No. 15-10197, \ 24 (Bankr. D. Del. 2015); see also Brickley, supra note 115 ("[T]hey say[] hedge funds engineered a bankruptcy crash landing designed to favor RadioShack's US:RSHCQ top-ranking lenders .....”); Tom Hals, Creditors Say RadioShack Timed Ch. 11 for Hedge Fund Trade: Filing, REUTERS (Feb. 18, 2015, 12:15 PM), https://www.reuters.com/article/us-radioshack-bankruptcy-creditors-idUSKBN0LM1PI20150218 ("Unsecured creditors of RadioShack Corp said the electronics retailer timed its bankruptcy to benefit a hedge fund trading strategy. ...").

123 Credit Derivatives Determinations Comms., Question Presented (Apr. 1, 2014), https://www.cdsdeterminationscommittees.org/documents/2014/12/20140401_questionpresented-v2.pdf; see also Rachelle Kakouris, ISDA Asked if RadioShack Triggered Credit Default Swaps via Lender Notice of Default, ForBes (Dec. 5, 2014, 10:46 AM), https://www.forbes.com/sites/spleverage/2014/12/05/isda-asked-if-radioshack-triggered-creditdefault-swaps-via-lender-notice-of-default/\#66bb29737d3e. 
"structured with a purpose to manipulate the CDS market" and, therefore, it ought to be disregarded and a credit event declared. ${ }^{124}$ The Determinations Committee, however, disagreed, finding that a credit event had not occurred, ${ }^{125}$ thereby guaranteeing that payments on RadioShack CDS of over $\$ 500$ million outstanding notional would not be triggered. ${ }^{126}$ Unsurprisingly (at least to the markets), RadioShack declared bankruptcy in February 2015 - two months after the expiration of CDS contracts held by RadioShack's last-minute lenders.

\section{Negating Default: The Case of McClatchy}

The final strategy that CDS investors may use to engineer CDS outcomes is to negate future possible defaults by "orphaning" the CDS. Here, a CDS protection seller offers financing to the issuer to restructure its debts. The debt restructuring, however, moves the debts off the balance sheets of the issuer and onto the balance sheets of a subsidiary or an affiliate. The result of the restructuring is to eliminate the future possibility of issuer default, as the issuer no longer has any outstanding debts. Thus, a CDS protection seller is guaranteed to keep the profits made on selling protection because the issuer's debt has been eliminated. Additionally, the CDS protection seller is entitled to continue collecting CDS premiums for the duration of the contract, despite there being no possibility of default in the future. By orphaning the CDS contract, the CDS protection seller guarantees that it will not be required to make CDS payments to its counterparties by negating potential defaults under the CDS contract. As with the prior strategies, this scheme works well with financially distressed companies because (i) the high premiums demanded for credit protection for such entities increase the profitability of selling protection and (ii) the company is likely willing to undertake such a scheme given its limited access to the credit markets.

An example of negating default involves the McClatchy Company ("McClatchy"). McClatchy is a highly indebted newspaper and online publishing company that experienced continued losses for over five years. ${ }^{127}$ In the first quarter of 2018, McClatchy entered into an agreement with Chatham Asset Management ("Chatham") to refinance most of its

124 CRedit Derivatives Determinations Comms., supra note 123; see also Phil Wahba, RadioShack Pulls the Plug and Files for Bankruptcy, FORTUNE (Feb. 5, 2015), http://fortune.com/2015/02/05/radioshack-bankruptcy-filing (stating that Standard General led a "rescue loan" for RadioShack).

125 CRedit Derivatives Determinations COMMS., supra note 123.

126 Kentz, supra note 121.

127 Ken Doctor, Gannett, McClatchy Close Out a Dismal Year, Politico (Feb. 9, 2017, 2:31 PM), https:/www.politico.com/media/story/2017/02/gannett-mcclatchy-close-out-a-dismal-year004930 (noting that, in 2017, McClatchy reported a revenue loss of $7.5 \%$ and a print ad loss of $20.6 \%$ for the fourth quarter). 
outstanding $\$ 710$ million debt. ${ }^{128}$ The refinancing agreement allowed McClatchy to reduce its debt load by approximately $\$ 50$ million and extend its loan maturity by two to seven years. ${ }^{129}$ However, the refinancing agreement had an important condition: A subsidiary of McClatchy would incur the debt for the refinancing and use the proceeds to purchase McClatchy's outstanding bonds. The refinancing meant that McClatchy would no longer have any outstanding debt; all of McClatchy's debt would be transferred to its subsidiary. ${ }^{130}$ Importantly, the subsidiary's debt was not covered under outstanding CDS contracts on McClatchy.

McClatchy's proposed refinancing concerned its CDS protection buyers, namely because it meant that they would hold orphaned CDS but would still be required to make premium payments on the CDS contracts. ${ }^{131}$ With McClatchy being a mostly debt-free entity, the likelihood of default for the ailing company was considerably reduced, making CDS protection purchased on McClatchy technically worthless. ${ }^{132}$ Unsurprisingly, Chatham was a major seller of McClatchy's CDS protection and, thus, stood to gain considerably from the transaction in two ways. The refinancing agreement meant that the CDS protection it sold on McClatchy could not be triggered, since McClatchy no longer had any debt. ${ }^{133}$ It also meant that Chatham could continue to collect CDS premiums for the life of the CDS contract, despite the elimination of McClatchy's indebtedness. ${ }^{134}$ By negating McClatchy's

128 McClatchy Reports Second Quarter 2018 Results, MCCLATChy (July 27, 2018), http://investors.mcclatchy.com/news-releases/news-release-details/mcclatchy-reports-secondquarter-2018-results?ID $=2360530 \& \mathrm{c}=87841 \& \mathrm{p}=$ irol-newsArticle (stating that McClatchy reported an adjusted net loss of $\$ 5.6$ million in the second quarter of 2018, and in July 2018 entered into a two-tranche Junior Lien Term Loan Agreement with Chatham Asset Management for \$157.1 million and \$193.5 million, respectively).

129 McClatchy had three loans outstanding, due in 2022, 2027, and 2029. The refinancing agreement extended the maturity on McClatchy's debt to 2030 and 2031. The McClatchy Co.,

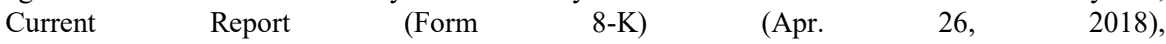
https://www.sec.gov/Archives/edgar/data/1056087/000114420418023038/tv492361_8k.htm.

130 Claire Boston \& Sridhar Natarajan, McClatchy Hands Win to CDS Buyers as It Tweaks Debt Deal, BLOOMBerg (Jun. 27, 2018, 11:11 AM), https://www.bloomberg.com/news/articles/201806-27/mcclatchy-hands-win-to-cds-buyers-as-it-tweaks-refinancing-deal.

131 Levine, supra note 12 (explaining that the deal between McClatchy and Chatham was "bad news for the hedge funds, banks and other investors that had bought insurance against a McClatchy default," essentially creating a scenario where "anyone who bought insurance on a McClatchy default would effectively be paying insurance on an entity with no significant debt").

132 See Sridhar Natarajan, Anchorage Caught Short in Chatham's McClatchy Trade, BLOOMBERG (May 2, 2018, 11:05 AM), https:/www.bloomberg.com/news/articles/2018-0502/anchorage-said-to-be-caught-short-in-chatham-s-mcclatchy-trade (highlighting that to the extent that the deal works out, "anyone who bought insurance on a McClatchy default would effectively be paying insurance on an entity with no significant debt" and that swaps would be "all but worthless").

133 See Levine, supra note 12 (detailing McClatchy's refinancing transaction which made defaults impossible).

134 Id. ("Chatham's CDS - which it sold at high prices reflecting McClatchy's low-junk Caa1/CCC+ credit ratings - will turn out to be free money."). 
future default, Chatham guaranteed the profitability of its CDS positions and did so at the expense of its counterparties.

III

\section{ASSESSING BENEFITS, COSTS, AND THE MARKET'S RESPONSES}

The market response to engineered CDS transactions has been mixed. Whereas some view engineered CDS as a useful innovation in the credit markets that have opened new financing pathways for distressed companies, ${ }^{135}$ others view the transactions as an exploitation of CDS that may constitute market manipulation. ${ }^{136}$ Implicit in discussions of the virtues and vices of engineered CDS is also an assessment of whether legal intervention is necessary or desirable to curtail these transactions. However, these are two separate albeit related questions. That is to say, identification of the externalities that accompany engineered CDS transactions is analytically distinct from determining whether these associated externalities justify legal involvement in the CDS markets. Yet, because the two issues are closely related, prior to addressing the latter issue, one must first assess the former, accounting for the positive and negative externalities that arise from engineered CDS transactions.

Part III analyzes the ex post and ex ante consequences of engineered CDS transactions to determine whether their costs outweigh their benefits. This Part considers whether parties to engineered CDS internalize costs arising from these transactions and to what extent these costs are externalized to third parties. The analysis of the effects on parties considers the costs of engineered CDS on the CDS counterparty that engineers the transaction (the "winning" counterparty), the counterparty that loses in the transaction (the "losing" counterparty), and the issuer that receives favorable financing. In assessing the effects on third parties, Part III considers the broader ramifications of engineered transactions for other market participants, who are not involved in engineered transactions. As analyzed in greater detail below, engineered transactions are net positive for issuers but, at best, are zero-sum for CDS counterparties. For non-parties, engineered CDS impose negative externalities, from both an ex post and an ex ante perspective, which are not offset by any benefits to the markets. Thus, in light of the negative

135 Fanni Koszeg, The Evolution of Credit Default Swaps and Efforts to Regulate Them: What Will Be the Impact of JP Morgan Chase's Recent \$2 Billion Trading Loss, BLOOMBERG (July 16, 2012), https://www.bna.com/evolution-credit-default-n12884910685 (noting that in 2002, Federal Reserve Board Vice-Chair Roger Ferguson stated that CDS "enhance economic efficiency" and "contribute to financial stability").

136 See Kadhim Shubber, CFTC: Deliberate Defaults May Be 'Market Manipulation,' Fin. TIMES (Apr. 4, 2018), https://www.ft.com/content/2f7f2b68-480e-11e8-8ee8-cae73aab7ccb. In response to Hovnanian's attempt to default as part of its debt refinancing plan with GSO, the CFTC stated that "[m]anufactured credit events may constitute market manipulation and may severely damage the integrity of the CDS markets." Id. 
externalities arising from engineered transactions, there is a strong justification for regulatory intervention in the market, despite the sophistication of the parties and the bilateral, contractual nature of their transactions.

Notwithstanding the associated negative externalities, to the extent the market can punish parties to engineered CDS transactions, forcing them to internalize the costs of these transactions, then legal intervention would not be needed. Part III assesses whether and to what extent market discipline can minimize the negative externalities engineered CDS produce. However, as discussed in Section III.C, market discipline is ineffective in the CDS market because of information asymmetry and high transaction costs, which renders market discipline impotent against engineered CDS transactions.

\section{A. The Consequences for the Parties}

To determine the effects of engineered transactions on the parties, it is necessary to consider their consequences, which allows for an assessment of their relative costs and benefits. Indeed, there is limited justification for legal intervention if engineered CDS impose costs that are either outweighed by their benefits or are internalized by CDS counterparties and the issuer, thereby resulting in a net neutral or net positive transaction. This Section first assesses the consequences of engineered transactions on the participating issuer and next, on the CDS counterparties.

The Participating Issuer. A positive view of engineered CDS is that it is a source of alternative financing for distressed issuers. An issuer facing financial distress must pay high interest rates to compensate creditors for the high risk of default. ${ }^{137}$ With engineered CDS, a financially distressed issuer can monetize its potential default or non-default by collaborating with the CDS counterparty that values it most, thereby transforming its distress into needed funding. For the issuer, there are no costs for which to account ex ante, particularly because it is not a party to the CDS contract. Ex post, however, engineered transactions impose costs on the issuer, including increased future funding costs because of reputational harm from engaging in an engineered transaction and potential negative effects on its non-CDS constituencies. ${ }^{138}$ Arguably, the issuer should have balanced the benefits of additional financing it would receive against costs of the transaction, including harm of the transaction to its reputation; legal costs that may stem

137 See Jorge A. Chan-Lau \& Yoon Sook Kim, Equity Prices, Credit Default Swaps, and Bond Spreads in Emerging Markets 3 (Int'l. Monetary Fund, Working Paper No. WP/04/27, 2004), https://www.imf.org/external/pubs/ft/wp/2004/wp0427.pdf.

138 See infra Section III.B for a discussion of costs to non-parties to the CDS markets, such as shareholders and creditors of the issuer. It is unlikely that the issuer will account for these thirdparty costs in deciding whether to participate an engineered transaction because the issuer does not bear these costs. As such, these third-party costs are not included in the analysis here. 
from the transaction; and future funding costs, as part of its decision whether to participate in an engineered transaction. Assuming that the issuer has properly accounted for such costs and has built these costs into its decision on whether to assist a CDS counterparty in engineering, engineered transactions are (or at least should be) net positive for a participating issuer.

CDS Counterparties. For the CDS counterparties, however, the calculus is different. The profits to the winning counterparty, on the one hand, and the losses to the losing counterparty, on the other hand, equal a zero-sum transaction between the CDS counterparties. ${ }^{139}$ Specifically, the benefits of an engineered CDS to both the issuer, in the form of better financing, and the winning CDS counterparty, in the form of a contract payoff, are entirely offset by costs to the losing CDS counterparty. Thus, as between CDS counterparties, engineered CDS transactions-similar to non-engineered CDS - do not create value. Rather, these transactions take wealth from one party and redistribute it to the other parties. ${ }^{140}$

However, closer analysis reveals that the ex post consequences of engineered CDS are not truly neutral, despite being zero-sum transactions. Counterparties to engineered transactions, especially the winning counterparty, incur "engineering" costs in executing the transaction. ${ }^{141}$ The engineering costs are twofold. First, there are the costs arising from arranging and executing the engineered transaction with the relevant issuer. These include research, negotiation, and general transaction costs associated with accomplishing the transaction. Additionally, to the extent CDS counterparties try to outbid each other for the issuer's default or non-default, the associated transaction costs are further increased. Second, there are the ex post information costs that CDS traders may incur to minimize the likelihood that they are the losers in an engineered CDS transaction. Faced with the likelihood that their counterparties may engineer their preferred outcome, CDS traders may incur significant information and research costs to determine whether their counterparties are incentivized to behave

139 A zero-sum game is one in which one party's gain stems directly from the losses of the other party; both parties cannot win. See Lawrence H. Summers \& Victoria P. Summers, When Financial Markets Work Too Well: A Cautious Case for a Securities Transactions Tax, 3 J. FIN. SERVS. RES. 261, 272 (1989) (recognizing that trading is a zero-sum game).

140 See Lynn A. Stout, Betting the Bank: How Derivatives Trading Under Conditions of Uncertainty Can Increase Risks and Erode Returns in Financial Markets, 21 J. CoRP. L. 53, 60 (1995) ("Speculative transactions of this sort would neither increase nor decrease the average derivative trader's wealth if dealing in derivatives were costless (although it might redistribute that wealth a fair bit).").

141 Even in the absence of engineered outcomes, CDS are zero-sum transactions that can be negative-sum because of the transaction costs associated with the trade, such as fees paid to swap dealers for facilitating the trade, premiums paid to protection sellers, and/or margin used as collateral for the trade, among other costs. See, e.g., id. at 61 (discussing that derivatives are innately zero-sum games which transform into negative sum games because of the associated transaction costs). These costs are not discussed because they are not unique to engineered CDS transactions but accompany all CDS transactions. 
opportunistically. ${ }^{142}$ Thus, an ex post cost of engineered CDS is greater information costs, for both counterparties, as they attempt to reduce the information asymmetry of the CDS transaction, thereby decreasing the risk of moral hazard. ${ }^{143}$ Arguably, the winning counterparty should have accounted for engineering costs in balancing the costs of engaging in an engineered CDS and the potential payout it would receive. The losing counterparty, on the other hand, may have underpriced the risk of engineering and, as such, may face higher than expected costs if the CDS is later engineered. But, given that either side may decide that it is worthwhile to engineer, both counterparties can account for engineering costs in deciding, in the first instance, whether to enter into a CDS transaction at all and, in the second instance, whether to attempt to avoid, manufacture, or negate the CDS's default.

In sum, if CDS counterparties account for engineering costs at the time of transacting, the ex post costs for either counterparty ought to be zero-sum, even if one party later decides to engineer the outcome of the CDS. CDS counterparties are sophisticated enough that each can balance the costs of winning and losing in an engineered CDS transaction and price the risk into the trade. Indeed, given that these are sophisticated actors, this conclusion is not surprising - in knowing that their counterparty may engineer, CDS traders can account for such risk in the price they demand for buying or selling protection. ${ }^{144}$ Thus, from the standpoint of the CDS counterparties, it is ambiguous as to whether legal intervention is necessary to protect them from engineered CDS transactions.

\section{B. The Consequences for Third Parties}

While CDS counterparties and issuers may balance the effects and price the costs of engineered CDS to themselves into their transactions, they cannot and do not account for how engineered transactions harm third parties. As evidenced by the 2008 crisis, CDS have far reaching repercussions on the broader financial markets, extending beyond counterparties and the CDS markets. ${ }^{145}$ Engineered CDS transactions are no

142 See infra Section III.C for a discussion on why it may be nonetheless difficult for counterparties to obtain this information even with diligent research.

143 Moral hazard arises when one party engages in high-risk conduct because they do not bear the consequences of their conduct. As a quasi-form of insurance, moral hazard is an innate risk associated with CDS. See Henderson, supra note 52, at 19 (stating that a similarity between credit derivatives and insurance is the presence of moral hazard). While the traditional concern with CDS is the moral hazard the protection buyer faces, via the empty creditor problem, engineered CDS transactions demonstrate that the risk of strategic behavior is symmetric and either the protection buyer or seller may engage in engineered CDS transactions. See supra Part II for a discussion of engineered transactions initiated by either the protection buyer or seller.

144 See, e.g., Levine, supra note 93 (stating that the only losers in engineered CDS transactions "were presumably sophisticated, well-informed traders at big banks").

145 See, e.g., Scott E. Harrington, The Financial Crisis, Systemic Risk, and the Future of 
different - the ex post and ex ante consequences of these transactions impact the CDS markets, CDS traders not party to engineered transactions, and nonCDS traders. The ex post and ex ante consequences of engineered CDS transactions are discussed respectively below.

\section{Ex Post Effects}

The nature of the CDS markets may cause one to consider engineered transactions to be the cost of doing business. As some have asserted and as the analysis of the ex post consequences for CDS counterparties confirms, losing counterparties in engineered CDS transactions are large, sophisticated parties that can account for the costs of these machinations. ${ }^{146}$ However, the effect of the engineered CDS transactions extends beyond large CDS traders and has a broader impact on the CDS market, other CDS traders, and, notably, non-CDS traders. There are two noteworthy ex post third-party externalities that arise from engineered CDS: (i) costs to the CDS markets because of the burden that engineered transactions put on the market's price discovery mechanisms and (ii) costs to non-CDS parties connected to the issuer, such as creditors and shareholders.

\section{a. Pricing Inefficiency in the CDS Market}

Pricing CDS is a complex undertaking that requires econometric calculations that are beyond the scope of this Article. ${ }^{147}$ Nonetheless, from a high level of abstraction, the price of a CDS reflects the likelihood of default of the referenced issuer. ${ }^{148}$ To price this risk, investors and the market consider three broad factors: (i) the current economic well-being of the issuer and its future plans for growth, (ii) the prospects of the issuer's industry, and (iii) the macro-economic trends, forecast, and risk factors of the issuer's geographic market. ${ }^{149}$ The market assesses each factor and, on the basis of known information and market expectations, it establishes a "spread" (i.e.,

Insurance Regulation, 76 J. RISK \& INS. 785, 787 (2009) (explaining the rise in CDS and their effect on the mortgage market, which eventually led to the financial crisis).

146 Levine, supra note 93.

147 See, e.g., Yuan Wen \& Jacob Kinsella, Credit Default Swap-Pricing Theory, Real Data Analysis and Classroom Applications Using Bloomberg Terminal 6-7 (unpublished manuscript) (on file with the New York University Law Review), https://data.bloomberglp.com/bat/sites/3/2016/10/WhitePaper_Wen.pdf.

148 See PRACTICAL LAW FIN. ET AL., supra note 89 ("Pricing of a CDS contract reflects: [t]he probability that a failure to pay will occur with respect to the reference entity, and [ $t$ ]he likely value of the CDS contract in the event a failure to pay does occur.").

149 CDS Spreads and the Impact of Spread Widening, FIN. TRAIN, https://financetrain.com/cdsspreads-and-impact-spread-widening (last visited Aug. 20, 2018) (stating that there are multiple factors apart from CDS spread that determine the credit risk of an entity, including "worsening macroeconomic conditions... the equity market's implied volatility, industry, leverage of the reference entity, the risk-free rate, and liquidity of the CDS contract"). 
price) to reflect the referenced issuer's default risk. ${ }^{150}$ A high(er) spread indicates a high(er) expected risk of default, whereas a low(er) spread indicates the converse. ${ }^{151}$ As the price of the CDS changes, the spread changes in response to both the supply and demand for the contract and relevant information that impacts the market's assessment of the issuer's credit risk. ${ }^{152}$ Therefore, the price of the CDS reflects the likelihood of the issuer's default as a result of its financial condition. ${ }^{153}$

Engineered CDS diminish the pricing efficiency of the markets by distorting the reliability of the CDS spread as a reflection of the issuer's risk of default arising from its financial condition. ${ }^{154}$ By divorcing default risk from the financial condition of the issuer, engineered CDS hamper price discovery and decrease the value of CDS prices as a source of information on the issuer. The consequences on the pricing efficiency of the CDS market are twofold, yet highly interrelated.

First, engineered CDS transactions reduce the value of the CDS spread as an indicator of the issuer's financial condition. In the absence of engineered transactions, CDS prices represent the market's estimation of the issuer's credit risk given its financial condition. ${ }^{155}$ Engineered transactions untether default risk from the issuer's financial condition and, consequently, there is a significant increase (decrease) of the CDS spread, despite there being no fundamental change to the issuer's financial condition. In each of the examples discussed above, the CDS prices of issuers participating in engineered transactions experienced sharp swings following the announcement of an engineered transaction, thereby diminishing the informational value of the CDS price to the markets. Engineered CDS make

150 See Hao Wang, Hao Zhou \& Yi Zhou, Credit Default Swap Spreads and Variance Risk Premia, 37 J. BANKING \& FIN. 3733, 3736 (2013) (explaining that the periodic payment that a protection buyer makes to the seller, as a percentage of the notional value of a bond is the CDS spread, which "[b]y definition ... provides a pure measure of the default risk of the reference entity").

151 See Jody LuRie, JANNey InV. StRATEgy Group, Clash of the Tightens: History of CREDIT SPREADS 1, 2 (2018), https://www.janney.com/File\%20Library/Unassigned/History-ofCredit-Spreads-2018-01-12.pdf (presenting a graph spanning eighteen years that documents defaulting events, such as the Lehman Brothers' collapse and AIG's bailout, which correspond to credit spread widening); Simon Constable, Why Tighter Credit Spreads Matter to Investors, WALL ST. J. (July 6, 2014, 4:47 PM), https://www.wsj.com/articles/why-tighter-credit-spreads-matter-toinvestors-1404679626 (stating that CDS spreads have shrunk in recent years which means "there is less risk of companies failing to pay the interest owed").

152 Mark J. Flannery et al., Credit Default Swaps as Viable Substitutes for Credit Ratings, 158 U. PA. L. REV. 2085, 2088 (2010).

153 See PRACTICAL LAW FIN. ET AL., supra note 89.

154 Prices are efficient when they quickly and accurately reflect available information. Zohar Goshen \& Gideon Parchomovsky, The Essential Role of Securities Regulation, 55 DuKE L.J. 711, 721 (2006) ("In efficient markets, information about the value of firms is incorporated quickly and accurately into stock prices.").

155 See, e.g., Colm Doherty, CDS as a Measure of Credit Risk, RisK.NET (Sept. 14, 2009), https://www.risk.net/derivatives/credit-derivatives/1533384/cds-measure-credit-risk. 
the spread a noisier, and therefore less useful, signal of the creditworthiness of the issuer because the spread is no longer representative of the issuer's financial condition.

Consider that an issuer may be a high credit risk because of its debt load or other economic factors, but the market did not consider it to be at a high risk of defaulting on its outstanding obligations. This was evident with Hovnanian's CDS. In the months preceding the GSO-Hovnanian deal, Hovnanian's CDS traded at approximately 1600 basis points ${ }^{156}$ and its S\&P credit rating was $\mathrm{CCC}+$, both of which indicated that the company was financially vulnerable but not expected to default on its obligations. ${ }^{157}$ After the GSO deal was announced, however, the spread doubled to over 3200 basis points, ${ }^{158}$ and its credit rating was downgraded to CC, despite the fact that Hovnanian's creditworthiness had not changed. Thus, Hovnanian's credit spread was no longer an accurate reflection of its financial condition, but instead reflected the market's expectation of its negotiated default. Engineered CDS transactions, therefore, distort the market's ability to provide an accurate portrayal of the financial condition of the issuer in its CDS spread, thereby denying the markets of socially beneficial information.

Second and relatedly, in the wake of, or in expectation of, an engineered transaction, the CDS spread becomes a reflection of the likelihood of engineering. With the default risk reflected in the CDS spread being unmoored from the issuer's financial condition, the CDS price becomes instead a signal of the market's assessment of the probability of an engineered transaction being announced or, if already announced, the probability of success of an engineered transaction resulting in default or non-default. Taken to its natural conclusion, in a market in which engineered transactions are feasible and permissible, the CDS spread of companies that could be targets of engineered transactions will increasingly reflect the risk of engineered-related outcomes, ${ }^{159}$ rather than the issuer's fundamental credit risk. This diminishes the market value of CDS prices and impedes the price efficiency of the CDS market to the detriment of all market

156 See Boston \& Natarajan, supra note 11 (showing Hovnanian's CDS prices from May 2017 to May 2018). This meant that it cost, for example, $\$ 1,600$ to insure $\$ 100,000$ od debt.

157 See Abdul Rehman Maqbool, S\&P Downgrades Hovnanian Enterprises Rating, S\&P GLOBAL (Apr. 8, 2018), https://www.spglobal.com/marketintelligence/en/newsinsights/trending/uvtrro477wphieoqofhbma2 (indicating Hovnanian's pre-GSO transaction credit rating); S\&P GLOBAL RATINGS, DEFINITIONS tbl.1 (2019), https://www.standardandpoors.com/en_US/web/guest/article/-/view/sourceId/504352 (discussing what a CCC rating means).

158 See Boston \& Natarajan, supra note 11 (showing Hovnanian's CDS prices from May 2017 to May 2018).

159 This refers to three things: (i) the likelihood of engineering occurring in the future; (ii) the likelihood of success (failure) of the engineered transaction; and (iii) the likelihood of default or non-default given the expected or proposed engineered transaction. In a market with engineered transactions, all three of these considerations are likely to be incorporated into the CDS spread as the market tries to anticipate the various facets of an engineered transaction in the markets. 
participants.

For example, prior to the McClatchy transaction becoming public, the company's CDS traded on average at 900 basis points or $9 \%$ of the contract-meaning, it cost approximately $\$ 900,000$ per year to insure $\$ 10,000,000$ of McClatchy's debt. ${ }^{160}$ After the announcement, the spread fell to almost 300 basis points, as the markets viewed CDS protection on the company to be null given the expected negating of the CDS contracts. ${ }^{161}$ The post-engineering price of McClatchy's CDS was not a result of any changes to McClatchy's financial condition. From a financial standpoint, the likelihood of McClatchy's default due to its financial condition had not changed. Rather, the sharp decline in price was due to the market's assessment of McClatchy's engineered-related default risk, which was much lower than the company's actual default risk, in light of the proposed engineered transaction. The engineered transaction, therefore, caused the CDS spread to reflect the probability of success of the announced engineered transaction, rather than McClatchy's true risk of default, that is, the risk of default given its financial condition.

\section{b. Costs to Non-CDS Traders}

Another consequence of engineered CDS is the impact such transactions have on non-CDS investors that are connected to the issuer. Specifically, the issuer's decision to participate in an engineered CDS transaction impacts third parties, such as creditors, suppliers, employees, and shareholders of the issuer. For example, engineered CDS transactions aimed at avoiding default through extension of a short-term loan harms the issuer's other creditors, particularly its unsecured creditors. Indeed, this was the basis of the complaint of RadioShack's unsecured creditors, which included employees, landlords, suppliers, and unsecured bondholders, after RadioShack received a loan that allowed it to temporarily avoid default. ${ }^{162}$ The company's unsecured creditors sought to have the last-minute loan excluded as a claim against RadioShack's bankruptcy estate on the grounds that the loan was extended primarily to control the timing of RadioShack's bankruptcy and to help CDS protection sellers avoid significant losses. ${ }^{163}$ This type of last-minute extension of credit does not represent a longer-term commitment to reviving the company or helping it avoid bankruptcy. Rather, it increases the company's indebtedness and must be accounted for in later, inevitable bankruptcy proceedings.

160 Boston \& Natarajan, supra note 130.

161 Id

162 See Order Pursuant to Section 105(a) of the Bankruptcy Code, Bankruptcy Rule 2004, and Local Bankruptcy Rule 2004-1, Authorizing and Directing the Examination of the Debtors and Certain Third Parties, In re RadioShack Corp., Case No. 15-10197, 550 B.R. 700 (Bankr. D. Del. Mar. 12, 2015) (No. 304).

163 Id. at $23-25$. 
For unsecured creditors of the issuer, engineered CDS transactions negatively impact them in two related ways. First, since the loan is shortterm focused-usually intended to help the issuer make it through two or three months - it does not trickle down to unsecured creditors; they remain unpaid despite the last-minute financing. Second, when the issuer later inevitably fails, the unsecured creditors' claims are likely to be subordinated to the short-term loan, which may be collateralized, thereby giving it priority over any unsecured claims. ${ }^{164}$ The short-term loan, therefore, only further decreases the likelihood that unsecured creditors will be paid at all from the bankruptcy assets.

Engineered CDS are also costly to the participating issuer's shareholders. Although participating in engineered CDS provides cheaper financing for financially distressed companies, involvement in these transactions likely exposes the company to lawsuits that are an added drain on corporate resources. ${ }^{165}$ For example, once Hovnanian and GSO agreed on a manufactured default, Hovnanian was sued by GSO's CDS counterparty. Defending itself against the suit, including motions, attorneys' fees, and countless hours from executives, imposes costs on Hovnanian's shareholders in the form of lost managerial time and likely decreased stock value. Indeed, the costs of potential legal action, including fines and penalties, are further increased if a regulator decides to investigate and bring an enforcement action against the company for its participation in an engineered CDS transaction.

\section{Ex Ante Effects}

Engineered CDS have three ex ante consequences on the markets and market actors, which further increase the costs associated with these transactions. Engineered CDS decrease CDS liquidity, impair market integrity, and negatively impact the availability of credit. Together, these consequences destroy the utility of CDS and the CDS market, imposing additional unaccounted for costs on third parties.

\section{a. Decreased Liquidity}

Engineered CDS transactions decrease the liquidity of the CDS market because traders are likely to withdraw from the markets owing to the decreased utility of CDS as risk mitigation tools. As discussed above,

164 See David Gray Carlson, A Theory of Contractual Debt Subordination and Lien Priority, 38 VAND. L. REV. 975, 991 (1985) ("[A] typical creditor should understand that subordination pertains to bankruptcy priority, and that subordinated debt falls behind other debt in that priority."). See generally Dee M. Calligar, Subordination Agreements, 70 YALE L.J. 376 (1961).

165 See Boston \& Natarajan, supra note 11 (describing a lawsuit brought by Solus Alternative Asset Management against Blackstone GSO Capital Partners). 
engineered CDS transactions undermine the pricing efficiency of the CDS markets by distorting the market's ability to accurately price the risk of default. A key component of pricing efficiency is market liquidity. Liquidity refers to the presence of other traders in the markets with whom one may readily transact. ${ }^{166}$ Pricing efficiency and liquidity have a symbiotic relationship - higher liquidity results in greater pricing efficiency and vice versa. ${ }^{167}$

Given the effect of engineered CDS on pricing efficiency, it is unsurprising that these transactions also negatively impact CDS liquidity. With the pricing accuracy of CDS being impaired, market participants are likely to withdraw from the CDS markets, diminishing the liquidity of the CDS market. ${ }^{168}$ Engineered CDS do not provide the insurance-like protection from default that make CDS valuable risk mitigation instruments, and thus they are of limited value to CDS counterparties who seek to use the instruments for hedging. Even for speculators, the proliferation of engineered transactions makes CDS an unwise investment. In the absence of engineering, CDS allow traders to diversify risk exposure according to the risk appetites of investors; engineering or the possibility thereof undermines the fundamental purpose of the instruments, transforming them almost entirely into gambling instruments that can be gamed. A rational investor is unlikely to invest in a CDS knowing that at any time her counterparty may engineer an outcome to her detriment. Indeed, many large investors that are active participants in the CDS markets have made statements to the press condemning these transactions and stating that it decreases the attractiveness of CDS. ${ }^{169}$ Thus, from an ex ante point of view, engineered CDS negatively affect the liquidity of the CDS markets as traders, including both hedgers and speculators, limit their participation in the markets to avoid being on the losing end of an engineered transaction.

166 DOUglas J. ELLIOTT, BROOKINGS InSTITUTION, MARKET LIQUidiTy: A PRIMER 3 (2015), https://www.brookings.edu/wp-content/uploads/2016/07/Market-Liquidity.pdf (providing a comparison between two markets exhibiting that liquidity emerges from ease of transactions based on time restraints, minimal transaction costs, and presence of potential buyers willing to pay theoretical market value)

167 Nicholas L. GEORGaKopoulos, THE LOGIC OF SECURITIES LAW 144 (“Greater trading activity translates to greater liquidity directly.... The economic force leading from liquidity to accurate prices rests on the reality that liquidity attracts informed trading.").

168 Childs, supra note 2 ("If users can't foresee and price such risks, they may stop using CDS altogether!").

169 See, e.g., Levine, supra note 12 (quoting a manager director at XAIA Investment as saying that "[ $[$ ] he whole market is losing credibility when you have events like this where you try to trigger the CDS or create orphaning situations"); Natarajan, supra note 178 (quoting a money manager at Resource America Inc. as saying that "CDS is being manipulated to the point that it potentially invalidates the product.... Fundamentally, markets rely upon valid prices. How can I use a product if I need to worry that counterparties are trying to vandalize capital structures to contort CDS contracts?"). 


\section{b. Impaired Market Integrity}

A noteworthy cost of engineered CDS is impairment of market integrity. Market integrity is a broad term that encapsulates the concept of market fairness, the absence of market abuse, and the protection of investors. ${ }^{170}$ It is an essential characteristic of a well-functioning market, as investors are only likely to participate to the extent they believe the markets are fair and are not stacked against them. ${ }^{171}$ If, on the other hand, investors believe the markets to be rigged, they are unlikely to enter the markets or, should they enter, they will discount the value of all transactions. ${ }^{172}$ Market integrity, therefore, is a bedrock component of the proper functioning of the financial markets. ${ }^{173}$

Despite its importance, the concept of market integrity can be somewhat amorphous, particularly in the CDS markets, where trading is a zero-sum game. ${ }^{174}$ However, while traders understand that the markets carry risk, which means their loss may be the result of another's gain, they do not expect those losses to be as a result of an unfair advantage. Thus, the concept of fairness cannot be overly broad to extend to any or all losses suffered in the market; losses are to be expected. Rather, to be a meaningful basis of analysis of market harm, fairness must be framed as the absence of unjust wealth transfers. As I explained in prior scholarship:

A transaction is unfair and harms the markets' integrity if it allows one trader to place her thumb on the scale such that the playing field is no longer level. This view of fairness rests on the reasonable expectations of the parties that their transactions have the same likelihood of success or failure. ${ }^{175}$

When considered in this light, it is evident that engineered CDS

170 Gina-Gail Fletcher, Legitimate yet Manipulative: The Conundrum of Open-Market Manipulation, 68 DUKE L.J. 479, 492 (2018).

171 See Robert J. Haft, The Effect of Insider Trading Rules on the Internal Efficiency of the Large Corporation, 80 MiCH. L. REV. 1051, 1051 (1982) ("If the public believes that the game is unfair and chooses not to play, the markets will suffer, and the efficient allocation of capital will be impeded."); Fletcher, supra note 170, at 489-90 (explaining that market manipulation "impairs the market's integrity because the conduct can lead other market participants to believe the market is unfair").

172 This is a classic lemons market as first described by George Akerlof: In a market in which buyers do not know which cars are worth their asking price and those that are not (i.e., lemons), the buyer will simply treat all cars like lemons. The result will be that worthy car sellers will leave the markets, being unable to get an accurate price for their product and lemon sellers will remain in the market. George A. Akerlof, The Market for "Lemons": Quality Uncertainty and the Market Mechanism, 48 Q.J. ECON. 488, 489-90 (1970); see also Richard Warner \& Robert H. Sloan, Vulnerable Software: Product-Risk Norms and the Problem of Unauthorized Access, 2012 U. ILL. J.L. TECH. \& POL'Y 45, 83 (2012).

173 See Akerlof, supra note 172, at 489-90 (illustrating how a violation of market integrity can adversely affect the stock price of a publicly traded corporation).

174 See Stout, supra note 140, at 745 (describing how "speculation on disagreement is a zerosum game in which one player's game is necessarily the other's loss").

175 Fletcher, supra note 170 , at 533. 
transactions are unfair, create the perception of the market being rigged, and undermine the integrity of the market. ${ }^{176}$ In collaborating with issuers to avoid, manufacture, or negate the issuer's default, CDS traders that engineer preferred outcomes undermine the reasonable expectations of their counterparties. ${ }^{177}$ Fundamentally, parties enter into CDS expecting that the ultimate determination of whether the contract pays off rests with market forces, over which neither party has control. However, when a counterparty interferes and skews the outcome of the CDS contract to her benefit, she undercuts her counterparties' reasonable expectations and unjustly transfers wealth from her counterparty to herself. As one CDS trader succinctly stated: "It's 100 percent fair to take the opposite side of a trade. ... But if then you do something bilaterally with the company, that isn't a fair trade." 178 Engineered CDS undermine the reasonable expectations of the markets, reducing the public's confidence and trust in the fairness of the market. ${ }^{179}$ And, importantly, as engineered transactions proliferate, it is likely that fewer investors will participate in the market, reducing it to a classic lemons market. The diminished integrity of the CDS market is a significant and costly consequence of engineered CDS and, if engineered transactions are allowed to thrive, they threaten the survival of the CDS market.

\section{c. Reduced Credit Market Liquidity}

A prime benefit of CDS is that they allow investors to offset and manage their risk exposure, thereby enhancing the liquidity of the bond market. With CDS, bondholders are able to lower their credit risk, which in

176 Levine, supra note 12 (recognizing that the CDS market is losing its credibility and its proper functioning); Matt Levine, RadioShack Is Running on Credit Derivatives, BLOOMBERG OPINION (Dec. 18, 2014, 3:48 PM), https://www.bloomberg.com/opinion/articles/2014-1218 /radioshack-is-running-on-credit-derivatives ("[I]t is a mistake to think of derivatives as purely zero-sum, two-party bets with no implications for the underlying thing. Those bets don't want to stay in their boxes; they want to leak out and try to make themselves come true."); Scurria, supra note 2 (stating that the GSO-Hovnanian transaction raised concerns about the vulnerability of the CDS market to manipulation and "undermin[ed] the usefulness of credit default swaps as an insurance product").

177 As the CFTC states: "The CDS market functions based on the premise that firms referenced in CDS contracts seek to avoid defaults, and as a result, the instruments are priced based on the financial health of the reference entity." CFTC Press Release, supra note 12. However, although the CFTC is only referring to manufactured defaults, the same is true for all strategies used to engineer CDS outcomes.

178 Sridhar Natarajan, This Hedge Fund Trade Is Stirring Fresh Controversy in the CDS Market, BLOOMBERG (Apr. 30, 2018, 11:12 AM), https://www.bloomberg.com/news/articles/2018-04-30/hedge-fund-gambit-stirs-freshcontroversy-in-besieged-cds-market (quoting XAIA Investment GmbH managing director Jochen Felsenheimer).

179 As discussed in Section III.C, infra, while these may be the reasonable expectations of CDS counterparties, they are explicitly disclaimed in the Master Agreement. That is to say, the Master Agreement allows parties to engage in self-interested conduct, thereby permitting the type of conduct underlying engineered CDS transactions. 
turn increases their willingness to extend more credit to other borrowers. ${ }^{180}$ By facilitating the transfer of long-term credit risk, CDS improve credit market liquidity as more investors are willing to lend in light of the insurance-like protections of CDS. ${ }^{181}$ Engineered CDS, however, not only reduce liquidity in the CDS market but also impair the availability of credit within the markets more generally.

From an ex ante standpoint, engineered CDS transactions diminish the risk mitigation capabilities of CDS. In the shadow of engineered transactions, investors are unable to rely on CDS to offset credit risk exposure and, as a result, they are less likely to extend credit to companies. Notably, engineered transactions affect credit availability for all companies that issue bonds or need loans, not merely past participants in engineered CDS transactions. An investor will not know prior to her bond purchase whether the company will participate in an engineered CDS scheme and thus may reduce her investments generally to limit her exposure. Alternatively, a bond investor that was willing to purchase bonds of companies with high credit risk may only purchase investment-grade bonds, recognizing that financially distressed companies are the most profitable targets for engineered transactions. Consequently, bond investors will begin restricting their participation in the credit market ex ante because of the reduced capability to use CDS for risk mitigation. The resulting restriction of credit within the markets will increase the cost of capital for many companies, and for financially distressed companies, it will compound their already precarious financial condition. In sum, these ex ante effects of engineered transactions are likely to spill into markets connected to the CDS market, affecting companies and market participants unrelated to engineered CDS transactions.

From both an ex post and ex ante standpoint, engineered CDS transactions impose costs on third parties that are not internalized by the parties to the transactions and, importantly, are not offset by any gains. Indeed, the far-reaching consequences of engineered CDS threaten the viability of the CDS markets, increase the cost of capital for issuers, diminish the utility of CDS as risk mitigation tools, and decrease the informational value of their prices. In exchange, engineered CDS do not provide any gains to the markets and, as such, the costs to third parties outweigh the non-

180 See Partnoy \& Skeel, supra note 26, at 1025 ("Because [CDS] limit the bank's downside risk (and pass it on to other parties, such as insurance companies and pension funds), banks are willing to lend much more money to many more businesses.").

181 Johnson, supra note 5, at 200 ("Multiple commentators have described credit default swaps as an instrument that completes credit markets because the instruments allow market participants to offset exposure to risk of loss."). 
existent benefits. The significant consequences to third parties strengthen arguments against engineered CDS transactions and likewise against those in favor of regulatory intervention or private remediation. However, as a market with sophisticated players, the possibility that the market may be able to curb costly conduct must be analyzed prior to considering whether external intervention in the market is needed. Therefore, before assessing regulatory and private rules applicable to engineered CDS transactions, Section III.C considers the extent to which market forces can address and minimize their attendant costs.

\section{The Limits of the Market's Responses}

To the extent the market can limit the costs of engineered transactions, external intervention into the market may be unnecessary. There are two potential market responses that could negate the need for regulatory involvement to cabin the consequences of engineered transactions. First, if CDS counterparties can effectively contract around engineered transactions, then there is little reason for intervention. Second, if market discipline can force CDS traders to internalize the costs of engineered transactions, there is little cause for concern or need for regulatory or private remediation. Neither response, however, is effective in the CDS market.

\section{Bilateral Amendments to the Master Agreement}

A reasonable market response to engineered transactions would be for CDS counterparties to bilaterally amend their CDS contracts. Parties to a CDS contract can modify clauses in the Master Agreement by including their amendments in the accompanying Schedule. ${ }^{182}$ Thus, a CDS trader could protect herself from engineered transactions by amending the CDS contract accordingly. Although amending CDS contracts individually is possible, it is rarely done, ${ }^{183}$ and, more importantly, it is unlikely market participants will do so even in the face of engineered transactions. A key factor in the value and liquidity of a CDS contract is its standardization. ${ }^{184}$ Standardized CDS contracts are more easily tradeable because the Master Agreement's default terms are familiar to the market and apply uniformly. ${ }^{185}$ A CDS trader

182 See supra note 67 and accompanying text (discussing amending the Master Agreement with Schedules).

183 See Norman Menachem Feder, Market in the Remaking: Over-the-Counter Derivatives in a New Age, 11 VA. L. \& Bus. REV. 309, 342 (2017) ("It could be said that standardizing OTC derivatives documentation begets a paradox: the more the OTC market relies upon a form or a standard set of terms, the less apparent room there is to negotiate bilaterally.").

184 See Nicholas Vause, Counterparty Risk and Contract Volumes in the Credit Default Swap Market, BIS Q. REV. 59, 62-63, Dec. 2010, https://www.bis.org/publ/qtrpdf/r_qt1012g.pdf (describing structural changes in the CDS market).

185 See Gelpern \& Gulati, supra note 78, at 361 (explaining that the liquidity of the CDS market is linked to the use of standardized contract terms). 
may elect to modify what constitutes a credit event under its CDS contract, but it will face higher transaction costs in buying (selling) credit protection in the first instance, and once again when it tries to trade the CDS in the future. Trade-by-trade amendments to CDS contracts on an individual, haphazard basis would increase transaction costs and CDS spreads while decreasing CDS liquidity. Additionally, altering the Master Agreement would increase contracting costs because the amendments would require bilateral negotiations pre-trade, and in the event of a credit event, additional negotiations or judicial intervention could be needed to interpret the contract. Thus, individually amending CDS contracts is not an effective market response to engineered transactions.

\section{Market Discipline}

Per the theory of market discipline, government or regulatory intervention may not be needed to correct market failures if the market can prevent or limit negative behavior through market-based mechanisms. ${ }^{186}$ Effective market discipline is based on two foundational conceptsmonitoring and influence. ${ }^{187}$ First, monitoring refers to the incentives for and capacity of market actors (i.e., monitors) to stay abreast of the actions of the "bad actor." 188 Effective monitoring depends on the ease with which market participants can access information about each other's decisions and actions. In opaque markets, with high information costs, market actors are less effective in disciplining the misconduct of bad actors through market-based means. ${ }^{189}$ Second, influence refers to the ability of market actors to persuade bad actors to change their behavior. ${ }^{190}$ Influence may come directly from market actors, who may believably threaten punishment or impose meaningful sanctions on bad actors. In so doing, market actors would not only penalize the bad actor but would also send a signal to future bad actors of their fate if they engage in similar conduct.

Market discipline is not an effective restraint on engineered transactions because of the inherent information asymmetry and high transaction costs

186 David Min, Understanding the Failures of Market Discipline, 92 WASH. U. L. REV. 1421, 1428 (2015). Market discipline is commonly associated with regulation of banks and financial institutions but has broader applicability to how the market, acting through affected market constituencies, may limit or address misconduct by other actors within the market through economic and market-based tools. See, e.g., Helen A. Garten, Banking on the Market: Relying on Depositors to Control Bank Risks, 4 YALE J. ON REG. 129, 129 n.1 (1986); Constantinos Stephanou, Rethinking Market Discipline in Banking: Lessons from the Financial Crisis 4 (The World Bank, Working Paper No. 5227, 2010).

187 Robert R. Bliss, Market Discipline: Players, Processes, and Purposes, in MARKeT DisCIPLINE ACROSS COUNTRIES AND INDUSTRIES 37, 39 (Claudio Borio et al. eds., 2004).

188 The phrase "bad actor" is used here to denote the person or entity whose behavior one seeks to discipline or punish through market forces.

189 Bliss, supra note 187 , at 39.

190 Id. 
that limit incentives to monitor, on the one hand, and the muted capacity of market actors to influence counterparties' conduct, on the other hand. To start, CDS market actors lack the necessary information and market transparency to monitor counterparties that may engage in engineered transactions. CDS counterparties transact through swap dealers-market intermediaries that trade in swaps, buying from and selling to investors as requested and needed. ${ }^{191}$ A CDS trader is therefore unlikely to know the identity of her counterparty and cannot serve as an effective monitor. ${ }^{192}$ And, even if a CDS trader is able to identify her counterparty, she would also need to determine whether the counterparty has any relationship with or interest in the issuer that could serve as the basis for an engineered transaction.

Assuming for the sake of the argument that a CDS trader is able to identify her counterparties, she must then invest further resources to identify linkages between the issuer underlying the CDS and the counterparty; additionally, she must continuously stay up to date on any changes in the counterparty's investment decisions that may be related to the issuer. As we consider the extent of these costs, it is imperative to note that the CDS trader would need to do this level of research into all her CDS positions involving an issuer that could be a target for engineering. The scope and associated costs of CDS investors' efforts would be significant, and ultimately the benefits - should any accrue - would be diffused among all CDS investors, regardless of whether they invested similar resources in monitoring.

It is also questionable whether market actors can influence parties engaged in engineered transactions to adjust or alter their conduct. Influence can only work to alter the conduct of the bad actor to the extent threatened sanctions are believable and punishment feasible. "Naming and shaming" those who engage in engineered CDS transactions is unlikely to persuade them to change because of the persistent informational asymmetry in the CDS market. The inability to identify one's counterparty, because trades are through an intermediary, means that reputational consequences lack teeth. Market discipline, therefore, is rendered ineffective in addressing engineered transactions because the market lacks the necessary influence to convince parties to not engage in engineered transactions.

In sum, market discipline does not mitigate against the costs that arise from engineered CDS transactions. The structure of the CDS market, in which monitoring costs are high and the ability to influence traders' conduct

191 See Intermediaries, supra note 50 (discussing the role of swap dealers in the CDS market). 192 See Final Rules Regarding Further Defining "Swap Dealer," "Major Swap Participant" and "Eligible Contract Participant," U.S. COMMODITY FUTURES TRADING COMM'N, https://www.cftc.gov/sites/default/files/idc/groups/public/@newsroom/documents/file/msp_ecp_f actsheet_final.pdf (last visited Apr. 8, 2019) (defining swap dealer and the relationship between swap dealers and swap participants); see also Mila Getmansky, Giulio Girardi \& Craig Lewis, Interconnectedness in the CDS Market, 72 FIN. ANALYSTS J. 62, 73-77 (2016) (providing statistical modeling to show the density of dealers to non-dealers in CDS contracts). 
is low, renders market discipline impotent in reducing the negative externalities that accompany engineered transactions. Given the negative externalities of engineered transactions on third parties and the failure of the market in effectively minimizing these costs, it is necessary to analyze whether and to what extent the applicable legal rules and private standards may be effective in limiting the consequences of these transactions. Yet, as is often the case with financial innovation, engineered transactions are beyond the scope of the applicable framework, leaving the markets exposed to significant negative externalities and denying market actors meaningful recourse to redress their harm.

IV

\section{APPLYING LAW TO ENGINEERED CDS}

The costs and consequences associated with engineered CDS provide a meaningful justification for external intervention to minimize the externalities of these transactions on third parties. However, as they have grown in visibility, some have questioned whether and to what extent the law or private rules can proscribe engineered CDS transactions. To date, there has been no judicial or regulatory decision with respect to the legality of engineered transactions, but lawmakers, market participants, and commentators have varied responses to this fundamental question. For example, in a public rebuke, the CFTC stated that manufactured defaults may constitute market manipulation. ${ }^{193}$ However, the Commissions have not yet brought any enforcement actions for engineered transactions, nor has it explained how or why these transactions constitute market manipulation under the existing legal framework. For its part, ISDA has amended its Determinations Committee procedures to address manufactured defaults. Owing to the limited scope of ISDA's amendments, however, their effectiveness in reducing the costs that accompany engineered transactions is constrained.

Part IV critically assesses three sources of laws and private rules applicable to CDS to determine whether they mitigate the costs arising from engineered CDS transactions. Specifically, Part IV examines the efficacy of: (i) federal anti-manipulation laws and regulations; (ii) contract common law; and (iii) ISDA's rules and procedures in proscribing or limiting the effects of engineered CDS transactions.

\section{A. Statutory Law: Anti-Manipulation Laws and Regulations}

CDS are subject to both the SEC and the CFTC regulatory regimes. ${ }^{194}$

193 CFTC Press Release, supra note 12.

194 "The SEC regulates CDS on single names, loans, and narrow-based security indexes. The CFTC regulates CDS based on broad-based security indexes." $Q \& A-$ Proposed Rules and 
Manipulation of the financial markets is prohibited primarily by the Securities Exchange Act of 1934 (the "Exchange Act") 195 and the Commodities Exchange Act of 1936 (the "CEA"). ${ }^{196}$ This Section first lays out the anti-manipulation framework under both regimes and then analyzes the obstacles to classifying engineered CDS as market manipulation.

\section{Anti-Manipulation Framework}

\section{a. The SEC and the Exchange Act}

Under the Exchange Act, the SEC is empowered to hold market actors liable for manipulation on the basis of price manipulation or fraud. ${ }^{197}$ Section 9(a)(2) of the Exchange Act prohibits transactions that alter the price of a security or security-based swap to induce another to buy or sell the security. ${ }^{198}$ The SEC has not relied extensively on section 9 because of its specific intent requirement, which has been a heavy burden for the agency to meet. 199

The SEC's preferred, broader anti-manipulation authority is found in section 10(b) of the Exchange Act, which authorizes the SEC to proscribe "any manipulative or deceptive device or contrivance" in relation to the purchase or sale of a security or security-based swap. ${ }^{200}$ Rule 10b-5, enacted based on section 10(b), more specifically prohibits fraud, deception, and material misstatements in the securities markets. ${ }^{201}$ In applying section 10(b) and Rule 10b-5, courts have interpreted market manipulation to be a species of fraud ${ }^{202}$ and as a result have imported common-law fraud principles into securities anti-manipulation law. ${ }^{203}$ To allege a claim under section $10(\mathrm{~b})$ and

Interpretive Guidance Further Defining "Swap," "Security-Based Swap," and "Security-Based Swap Agreement"; Regarding "Mixed Swaps"; and, Governing Books and Records for "SecurityBased Swap Agreements," U.S. COMMODITY FUTURES TRADING COMM'N, https://www.cftc.gov/sites/default/files/idc/groups/public/@newsroom/documents/file/pd_qa.pdf (last visited Mar. 12, 2019).

195 Securities Exchange Act of 1934 § 9, 15 U.S.C. § 78(i) (2012).

196 Commodity Exchange Act of 1936 § 6(c), 7 U.S.C. § 9 (2012).

197 The SEC also may hold market participants liable for manipulation for fictitious trades in which a trader working alone or in concert with others pretends to trade assets but with no change in beneficial ownership. Examples of fictitious trades include wash sales and matched orders. See Securities Exchange Act of 1934 § 9(a)(1). However, fictitious transactions are not applicable to engineered CDS transactions and, as such, are not discussed herein.

19815 U.S.C. $\$ 78 \mathrm{i}$.

199 Fletcher, supra note 170, at 501 ("The requirement that the plaintiff prove both specific intent and price artificiality is the reason the SEC has avoided pleading price artificiality to prove manipulation ....").

20015 U.S.C. $\S 78 \mathrm{j}$.

201 Employment of Manipulative and Deceptive Devices, 17 C.F.R. $\S 240.10 b-5$ (1978).

202 Indeed, Rule 10b-5 equates manipulation with fraud in two out of three of its provisions. See Charles R. Korsmo, Mismatch: The Misuse of Market Efficiency in Market Manipulation Class Actions, 52 WM. \& MARY L. REV. 1111, 1120-22 (2011) (discussing the scope of Rule 10b-5).

203 See, e.g., Donald J. Polden, Drawing the Appropriate Statute of Limitations in Implied 
Rule $10 \mathrm{~b}-5$, the plaintiff must prove: (i) the defendant made a material misstatement or omission or used a fraudulent device; (ii) that she did so with scienter (i.e., intent); (iii) the defendant's conduct was related to the purchase or sale of a security; (iv) the plaintiff detrimentally relied; and (v) the plaintiff was harmed. ${ }^{204}$ Key to a Rule $10 \mathrm{~b}-5$ action, therefore, is a showing of fraud or material misstatement, without which is it difficult to hold a trader liable for fraud-based market manipulation.

\section{b. The CFTC and the CEA}

The CFTC's anti-manipulation framework is similar to that of the SEC's and includes prohibitions against price manipulation and fraud in the commodities markets. ${ }^{205}$ In 2010, the CFTC's anti-manipulation authority expanded to include anti-fraud provisions based on section 10(b) of the Exchange Act. ${ }^{206}$ Section 6(c)(1) of the CEA and the accompanying Rule 180.1, which mirrors Rule 10b-5, prohibit fraud-based manipulation in the commodities markets. ${ }^{207}$ In modeling Rule 180.1 on Rule $10 \mathrm{~b}-5$, the CFTC explicitly and implicitly incorporated Rule $10 \mathrm{~b}-5$ 's extensive jurisprudence and precedence. ${ }^{208}$

Prior to this legislative expansion of its authority, price manipulation was the CFTC's only avenue for holding market actors liable for market manipulation. ${ }^{209}$ To allege price manipulation under the CEA, the plaintiff is required to prove four elements: (i) a manipulative act or omission; (ii) intent; (iii) causation; and (iv) artificial price. ${ }^{210}$ Scienter has been an almost

Causes of Action Under Rule 10b-5: A General Framework of Familiar Legal Principles, 40 DRAKE L. REV. 221, 248 (1991) ("[I]t appears that the courts have been interpreting Rule 10b-5 in harmony with the elements of state common law fraud actions.").

204 See ATSI Commc'ns, Inc. v. Shaar Fund, Ltd., 493 F.3d 87, 105 (2d Cir. 2007).

205 Fletcher, supra note 170, at 495-97.

2067 U.S.C.A. \& 9(1) (West 2018). See Prohibition on the Employment, or Attempted Employment, of Manipulative and Deceptive Devices and Prohibition on Price Manipulation, 76 Fed. Reg. 41398, 41398 (July 14, 2011) (explaining the expanded scope of the CEA's regulatory jurisdiction under Dodd-Frank).

207 Prohibition on Employment, or Attempted Employment, of Manipulative Deceptive Devices, 17 C.F.R. $\S 180.1$ (2019)

208 Prohibition on the Employment, or Attempted Employment, of Manipulative and Deceptive Devices and Prohibition on Price Manipulation, 76 Fed. Reg. at 41399 ("Given the similarities between CEA section 6(c)(1) and [SEA] section 10(b), the [CFTC] deems it appropriate ... to model final Rule 180.1 on SEC Rule 10b-5... . [T] he [CFTC] will be guided, but not controlled by the substantial body of judicial precedent applying the comparable language of SEC Rule 10b-5.”).

209 See Andrew Verstein, Benchmark Manipulation, 56 B.C. L. REV. 215, 254 (2015) (“After decades of the CFTC attempting to win manipulation cases without alleging fraud, Congress has seemingly ratified the judicial focus on fraud, by including in Dodd-Frank statutory language granting the CFTC fraud-based manipulative enforcement authority.").

210 See DiPlacido v. CFTC, 364 F. App'x 657, 661 (2d Cir. 2009); In re LIBOR-Based Fin. Instruments Antitrust Litig., 27 F. Supp. 3d 447, 466 (S.D.N.Y. 2014); CFTC v. Wilson, 27 F. Supp. 3d 517, 531 (S.D.N.Y. 2014); In re Commodity Exch. Inc., Silver Futures \& Options Trading Litig., 2012 U.S. Dist. LEXIS 181487, at *45-46 (S.D.N.Y. Dec. 21, 2012); CFTC v. Amaranth 
insurmountable barrier for the CFTC in prosecuting manipulation because it must prove that the defendant had the specific intent to create an artificial price. ${ }^{211}$ Indeed, the CFTC won its first non-fraud manipulation case in 2009, approximately thirty years after its founding. ${ }^{212}$ Additionally, proving price artificiality is also difficult because of the difficulty of defining when or why a price becomes artificial. Consequently, in the absence of wrongful conduct, courts are unlikely to find that a price is manipulated.

\section{Application to Engineered CDS}

There are three primary obstacles that limit the reach of the antimanipulation framework to engineered CDS transactions-(i) proving price artificiality; (ii) the absence of fraud or misrepresentation; and (iii) proving manipulative intent.

\section{a. Price Artificiality}

The first obstacle to proving price manipulation with engineered CDS transactions is demonstrating that the price is artificial. A price is considered artificial if it does not represent natural forces of supply and demand. ${ }^{213}$ Trading undertaken to create false signals of increased (or decreased) market interest in an asset generates an artificial price and, therefore, constitutes illegal market manipulation. ${ }^{214}$ Setting aside for the moment the more difficult question of how one delineates between natural and unnatural forces of supply and demand, it is difficult to see how engineered transactions cause an artificial price under this legal formulation of artificiality. The resulting (albeit volatile) price of a CDS contract in the wake of an engineered transaction is set through market forces. As the market learns of an impending manufactured default, for example, protection sellers rationally and reasonably will charge more to the extent they remain willing to sell credit protection. The pricing of the CDS, undoubtedly, has become inefficient, as the spread no longer reflects the financial condition of the reference entity; but, notably, the price is the result of legitimate market

Advisors, L.L.C., 554 F. Supp. 2d 523, 532 (S.D.N.Y. 2008).

211 See Craig Pirrong, Commodity Market Manipulation Law: A (Very) Critical Analysis and a Proposed Alternative, 51 WASH. \& LEE L. REV. 945, 984-88 (1994) (discussing the difficulty with the predominant view of intent).

212 DiPlacido is the first manipulation case that the CFTC has prosecuted successfully in its history. This does not include settlements for manipulation over the decades. See DiPlacido, 364 F. App'x at 659 (affirming the decision of the CFTC to apply sanctions for manipulation); see also Fletcher, supra note 170, at $501 \mathrm{n} .85$; Andrew Longstreth, Analysis: CFTC Faces High Hurdles in Oil Manipulation Case, REUTERS (May 26, 2011), https://www.reuters.com/article/us-arcada-cftclawsuit/analysis-cftc-faces-high-hurdles-in-oil-manipulation-case-idUSTRE74P6GF20110526.

213 See Ronald W. Anderson, Credit Default Swaps: What Are the Social Benefits and Costs?, 14 Fin. STABILITY REV. 4-5 (2010) (discussing the use of CDS to leverage transactions).

214 See Daniel R. Fischel \& David J. Ross, Should the Law Prohibit "Manipulation" in Financial Markets?, 105 HARV. L. REV. 503, 507 (1991) (defining market manipulation). 
transactions in response to non-deceptive disclosures of an impending default. This may seem to be a fine hair to split, but it is a distinction worth making. Thus, although the CDS spread post-engineering is untethered from the financial condition of the issuer, it is the market-driven price and, therefore, not artificial under the existing legal framework.

An argument could be made that because engineered transactions distort the informational value of CDS spreads as a reflection of the creditworthiness and risk of default of the issuer, they manipulate the price of the CDS. However, this would require a redefinition of "artificial" which courts may not be willing to do, particularly within the confines of a contract between sophisticated, well-informed parties. ${ }^{215}$ Indeed, while engineered transactions cause CDS spreads to no longer provide the markets with accurate information on the financial condition of the issuer or its true likelihood of default, this inaccuracy is not the result of what existing law considers to be false market signals. Rather, the inaccuracy of the spread arises because engineered transactions divorce financial condition from default and not because of unnatural market forces. Thus, despite distorting the price discovery mechanism of the markets, engineered CDS do not result in price manipulation under the current conceptualization of artificiality in anti-manipulation law.

\section{b. Fraud and Material Misstatements}

A second obstacle to holding a trader liable for market manipulation is the absence of fraud or misstatements in engineered CDS transactions. Engineered CDS transactions do not involve fraud or deception either by the CDS investor proposing the transaction nor by the issuer. Rather, depending on the significance of the financing, issuers may be required to release a Form 8-K to inform the markets of the proposed financing, identifying the lenders and, if applicable, any conditions attached to the transaction. For example, Hovnanian disclosed all the material terms of its financing transaction with GSO in its Form 8-K, including the condition that it miss its upcoming interest payment in order to receive the loan. ${ }^{216}$ Providing a loan to a distressed company does not fit the standard definition of fraud or misrepresentation in anti-manipulation law. Likewise, although manufactured defaults and orphan CDS transactions may seem unfair, they are contractually permitted and, legally, do not constitute fraud or misrepresentation. Thus, a primary avenue for proving market manipulation is not available in holding CDS counterparties liable for engineered

215 See, e.g., CFTC v. Wilson, No. 13 Civ. 7884, 2018 WL 6322024 (S.D.N.Y. Nov. 30, 2018) (rejecting CFTC's claim of market manipulation on the basis that the defendant's conduct was contractually permissible, among other reasons).

216 Hovnanian Enterprises, Inc., Current Report (Form 8-K) (Apr. 26, 2018), https://www.sec.gov/Archives/edgar/data/357294/000143774918010943/hov20180529_8k.htm. 
transactions.

\section{c. Manipulative Intent}

Third, underlying both price and fraud-based manipulation claims is the requirement of scienter. Scienter is a necessary element to holder a trader liable for market manipulation, and it is questionable whether regulators would be able to meet their burden. ${ }^{217}$ Recall that to prove price artificiality, regulators must demonstrate that the plaintiff had the specific intent to create an artificial price. Historically, this has been a difficult burden for regulators to meet, and it is unlikely to be any easier with engineered CDS transactions. To succeed on this element, plaintiffs must demonstrate defendants' intentional or willful efforts to deceive others. ${ }^{218}$ However, if regulators lack a "smoking gun" as unequivocal proof of the manipulative intent of the engineered CDS traders, such as explicit statements of the intent to manipulate the markets, proving specific intent in these transactions will be nearly impossible. ${ }^{219}$

Alternatively, regulators may attempt to hold engineered CDS investors liable through the general anti-fraud manipulation provisions on the basis that these transactions constitute open-market manipulation. Open-market manipulation is market manipulation accomplished through facially legitimate transactions executed on the open market. ${ }^{220}$ The Commissions' long-held position is that open-market trades constitute market manipulation if the trader had the intent to manipulate the market. ${ }^{221}$ Thus, engineered CDS transactions could qualify as open-market manipulation, if the Commissions are able to prove the intent to manipulate. The evidentiary bar in this instance is lower - the Commissions would only be required to prove the general intent to manipulate 222 _ but it would nonetheless be a difficult burden to meet.

Specifically, with facially legitimate transactions, the accused may rebut allegations of manipulation by showing legitimate, business-related motivations for the transaction. ${ }^{223}$ Counterparties that engage in engineered CDS transactions can assert a non-manipulative business purpose for the transactions, unrelated to market manipulation. With a legitimate,

217 See Pirrong, supra note 211, at 984-88 (discussing the difficulty with the predominant view of intent).

218 ATSI Commc'ns, Inc. v. Shaar Fund, Ltd., 493 F.3d 87, 100 (2d Cir. 2007).

219 Fletcher, supra note 170, at 515-16 ("Rarely is direct evidence of a defendant's manipulative intent available. ... Absent explicit or direct proof of a trader's intent to manipulate, plaintiffs and fact finders must infer intent from circumstantial evidence.”).

220 Id. at 516.

221 Id. at 502.

222 See 17 C.F.R. $\$ 240.10 b-5$ (2018) (codifying the prohibitions of fraud-based manipulations); see also Merritt B. Fox, Lawrence R. Glosten \& Gabriel V. Rauterberg, Stock Market Manipulation and Its Regulation, 35 YALE J. ON REG. 67, 117 n.117 (2018); Fletcher, supra note 170, at 540.

223 See SEC v. Masri, 523 F. Supp. 2d 361, 373 (S.D.N.Y. 2007). 
economically rational explanation, it is unlikely that a regulator's circumstantial allegations of manipulative intent will suffice. Indeed, the CFTC recently suffered a significant loss in its prosecution of open-market manipulation in CFTC v. Wilson. ${ }^{224}$ The CFTC alleged that the defendant, Don R. Wilson and his trading firm (collectively "DRW") exploited the terms of an interest rate swap contract for their benefit, manipulating the market in the process. The defendant, however, presented a legitimate business explanation for their conduct, denying that they were manipulating the market with their transactions. Faced with the defendant's economically rational explanation for his conduct on the one hand, and the CFTC's circumstantial evidence of manipulative intent on the other hand, the court unequivocally rejected the Commissions' claims, stating that "it is not illegal to be smarter than your counterparties in a swap transaction." 225

In sum, given recent court decisions on the issue of manipulative intent for open-market transactions, it is unlikely that the Commissions would be able to meet their evidentiary burden to prove market manipulation for engineered CDS transactions. The existing anti-manipulation framework is ill-suited to proscribe and punish engineered CDS transactions because the underlying conduct is permissible and proving the intent to manipulate would be a Herculean task for the Commissions. Thus, despite the proclamations of the Commissions on the matter, it is doubtful that CDS counterparties participating in engineered CDS transactions could be held liable for market manipulation.

\section{B. Contract Common Law}

As contracts, CDS are subject to contract common law if parties disagree as to the validity and interpretation of its terms. In interpreting a contract, courts rely on canons of contract interpretation, even for standardized contracts like the ISDA Master Agreement. ${ }^{226}$ Under the principles of contract interpretation, a court first attempts to identify the intent of the parties at the time of contracting from the language of the contract. ${ }^{227}$ If the parties' intent is unclear, the court considers the course of the parties' dealings and performance to ascertain their intent. ${ }^{228}$ The court may also examine industry custom and practice to decipher the expectations of the parties. ${ }^{229}$ Importantly, in interpreting parties' obligations, courts apply the implied covenant of good faith and fair dealing to ensure that parties do

224 CFTC v. Wilson, No. 13 Civ. 7884, 2018 WL 6322024 (S.D.N.Y. Nov. 30, 2018).

225 Id. at $* 21$.

226 See Choi \& Gulati, supra note 76, at 1141.

227 Keith A. Rowley, Contract Construction and Interpretation: From the "Four Corners" to Parol Evidence (and Everything in Between), 69 Miss. L.J. 73, 79-80 (1999).

228 See Omri Ben-Shahar, The Tentative Case Against Flexibility in Commercial Law, 66 U. CHI. L. REV. 781, 787 (1999).

229 Id. at 812. 
not avoid their expected duties under the contract. The implied covenant assumes that neither party will act in such a way that will destroy or injure the right of the counterparty to receive the benefit of the contract. ${ }^{230}$ However, to determine whether the covenant of good faith and fair dealing has been breached, the court also examines the language of the contract, the course of dealings of the parties, and the performance of the contract. ${ }^{231}$

Initially, the implied covenant of good faith and fair dealing appears to circumscribe CDS counterparties' engagement in engineered CDS transactions. By negotiating with the issuer to guarantee a preferred outcome, the counterparty is interfering with the contract in order to deny her counterparty's right to benefit from the CDS. However, the ISDA Master Agreement includes a provision which must be taken into account in assessing the applicability of good faith and fair dealing. Under the Master Agreement, each party is expressly allowed to transact without regard for the CDS, and, importantly, each is allowed to engage in transactions involving the underlying referenced asset, including "any action which might constitute or give rise to a Credit Event"232 (the "Self-Interest Provision"). That is to say, the ISDA Master Agreement explicitly permits CDS counterparties to enter into transactions related to or directly involving the debt underlying the CDS, without regard for the existence of the CDS or the interests of the CDS counterparty. In light of the Self-Interest Provision, it is questionable whether engineering one's preferred outcome in a CDS transaction breaches the implied covenant of good faith and fair dealing in the ISDA Master Agreement.

In a recent case, the New York state appellate court addressed the implications of the implied covenant of good faith on a CDS counterparty's self-dealing conduct under the Master Agreement given the Self-Interest Provision. ${ }^{233}$ In Good Hill Master Fund L.P. v. Deutsche Bank AG, Good Hill and Deutsche Bank entered into a CDS agreement that referenced a series of residential mortgage-backed securities ("RMBS") that Good Hill purchased from Bank of America. Under the CDS agreement, Good Hill was the protection seller and was obligated to compensate Deutsche if the underlying experienced a write-down or forgiveness of the principal. ${ }^{234}$ To secure its obligation, Good Hill posted collateral with Deutsche Bank to ensure payment should a credit event occur. A year later, owing to declining market conditions, Bank of America sought to repurchase the RMBS from Good Hill, which would be a credit event under the Good Hill-Deutsche

230 See, e.g., Tractebel Energy Mktg., Inc. v. AEP Power Mktg., Inc., 487 F.3d 89, 98 (2d Cir. 2007).

23123 WiLLISTON ON CONTRACTS $\S$ 63:22 (4th ed. 2019).

232 ISDA Credit Definitions Section 11.1(b)(iii) (2014).

233 Good Hill Master Fund L.P. v. Deutsche Bank AG, 146 A.D.3d 632 (N.Y. App. Div. 2017).

234 Id. at 633. 
CDS agreement. ${ }^{235}$ To decrease its liability under the CDS agreement, Good Hill negotiated price and payment allocation with Bank of America on the repurchase of the RMBS. Based on the negotiated repurchase price of the RMBS, Good Hill owed Deutsche $\$ 5$ million under the calculations specified in the CDS agreement; Deutsche at the time held \$27 million in collateral from Good Hill. ${ }^{236}$ However, Deutsche refused to accept the negotiated repurchase price and payment allocation and refused to return the excess collateral to Good Hill. ${ }^{237}$

In the ensuing lawsuit, Good Hill sued for return of its collateral and a breach of contract. Deutsche Bank defended its actions, alleging that Good Hill breached the implied covenant of good faith and fair dealing under the CDS contract by "engineer[ing] [a] commercially unreasonable and untenable... purchase price" for the RMBS. ${ }^{238}$ The appellate court, however, disagreed with Deutsche Bank, affirming the decision of the trial court. According to the court, Good Hill's negotiations with Bank of America were at arm's length, and, despite being aggressive, the negotiations were done in good faith. ${ }^{239}$ Further, the court noted, the implied covenant of good faith and fair dealing does not impose any obligations beyond the terms of the contract and it cannot impose duties that would contradict other terms of the contract. ${ }^{240}$ In light of the Self-Interest Provision, Good Hill was permitted to both (i) enter into transactions involving the RMBS underlying the CDS and (ii) pursue its own interests even if its actions may be detrimental to Deutsche Bank's interests. ${ }^{241}$ In concluding, the court stated that Deutsche Bank failed to meet its burden of proving Good Hill acted in bad faith in breach of the CDS contract.

In light of the Self-Interest Provision and the Good Hill holding, it is not likely that engineered CDS transactions would be considered a breach of the covenant of good faith and fair dealing. The collaboration between a CDS counterparty and the issuer is typically an arm's length transaction in which the CDS counterparty is negotiating a financing transaction and, as consideration, the issuer agrees to certain conditions that impact the CDS. Furthermore, the Self-Interest Provision explicitly allows parties to act in their own self-interest without regard for the CDS contract. In the absence of bad faith conduct on the part of the CDS counterparty in undertaking the engineered CDS transaction, it is unlikely that the covenant of good faith and fair dealing is breached. The gain of one CDS counterparty at the expense of

235 Id. at 634.

236 Id. at 635.

237 Id. at 636.

238 Good Hill Master Fund L.P. v. Deutsche Bank AG, No. 600858/2010, 2016 WL 3580032

at*15 (N.Y. Sup. Ct. Feb. 3, 2016).

239 Good Hill Master Fund L.P. v. Deutsche Bank AG, 146 A.D.3d 632 (N.Y. App. Div. 2017).

240 Good Hill, 2016 WL 3580032, at*16.

241 Id. at *16-17. 
the other does not constitute a breach of the covenant of good faith and fair dealing without additional bad faith actions. Indeed, a party to a contract is entitled to act in her own self-interest provided that her conduct is consistent with the terms and conditions of the contract. ${ }^{242}$ In a nutshell, this describes the conduct of CDS counterparties who participate in engineered transactions - they are acting in their own self-interest and in accordance with the terms of the CDS contract; thus, they are unlikely to be in violation of the covenant of good faith and fair dealing.

\section{Private Law: ISDA's Rules and Governance}

ISDA's role in the CDS markets makes it the natural problem-solving entity for engineered CDS. Despite being fiercely protective of the Master Agreement in some instances, ${ }^{243}$ ISDA's response to engineered CDS has been lukewarm, at best. It made no changes to the Master Agreement in response to Codere, nor did it express disapproval of the transaction; rather, the association was silent in the face of early iterations of engineered CDS. It was only after negative press reports on and significant market backlash to the Hovnanian transaction that ISDA spoke out against engineered transactions. ${ }^{244}$ Slowly, more than a year after the Hovnanian-GSO transaction was discarded, ISDA proposed amendments to the Master Agreement to address engineered CDS transactions, but in a limited manner.

In August 2019, ISDA finalized and published amendments to the 2014 Credit Derivatives Definitions to limit the availability of engineered CDS transactions, specifically, manufactured defaults (the "Amended Definition"). ${ }^{245}$ As with all ISDA amendments, market participants' adherence to the new provision is entirely voluntary and such adherence is effectuated through signing the related protocol. ${ }^{246}$ When first proposing the Amended Definition, ISDA noted that it would be exceedingly difficult for it to draft a comprehensive definition of what constitutes a manufactured

242 See Citibank N.A. v. United Subcontractors, Inc., 581 F. Supp. 2d 640, 646 (S.D.N.Y. 2008), aff'd, 355 F. App'x 507 (2d Cir. 2009) (stating in relation to the duty of good faith and fair dealing that "[a] party to a contract is allowed to act in its own self-interest consistent with its rights under the contract").

243 Choi \& Gulati, supra note 76, at 1144-46 (2006) (discussing ISDA's swift intervention into the CDS markets when the ISDA Master Agreement is threatened with misinterpretation).

244 See Press Release, Int'l Swaps \& Derivatives Ass'n, supra note 15 ("We believe that narrowly tailored defaults, those that are designed to result in CDS payments that do not reflect the creditworthiness of the underlying corporate borrower . . could negatively impact the efficiency, reliability and fairness of the overall CDS market.").

245 InT'L Swaps \& Derivatives ASS'N, 2019 NARrowly TAILORED CREdit Event SuPPLEMENT TO THE 2014 ISDA CREDIT DERIVATIVES DeFINITIONS (2019), https://www.isda.org/a/KDqME/Final-NTCE-Supplement.pdf (referring to manufactured defaults as "narrowly tailored credit events").

246 INT'L SwAPS \& DERIVATIVES ASS'N, ISDA 2019 NTCE PROTOCOL (2019), https://www.isda.org/a/31AME/08272019-NTCE-Protocol-Publication.pdf. 
default that would not be subject to the risk of being undermined by parties in the future. ${ }^{247}$ Thus, the Amended Definition addresses manufactured defaults by focusing on its most salient characteristic: namely, the decoupling of the issuer's creditworthiness or financial condition from its likelihood of default on its debt obligations. ${ }^{248}$

With the Amended Definition, ISDA circumscribes manufactured defaults by expanding what constitutes "Failure to Pay" under the Master Agreement. Specifically, an issuer's default on outstanding debts does not constitute a Failure to Pay if "such failure does not directly or indirectly either result from or result in a deterioration in the creditworthiness or financial condition" of the issuer. ${ }^{249}$ Under the "Credit Deterioration Requirement," there must be a causal link between the issuer's default and its declining creditworthiness or economic condition. ${ }^{250}$ Notably, the Determinations Committee would be responsible for deciding whether a default is a contractually valid Failure to Pay. In making its determination, the Determinations Committee would be allowed, but not required, to consider external information that may assist it in making its decision. Additionally, the Amended Definition lists a non-exhaustive set of factors that may indicate that the Credit Deterioration Requirement has not been met, including: (i) the default resulted from an arrangement with the issuer for the purpose of benefitting a counterparty to a CDS; (ii) the default is quickly cured after the grace period; or (iii) the issuer has sufficient liquidity to meet its debt obligations, among other reasons. ${ }^{251}$

The Amended Definition is a positive, first step towards addressing engineered CDS transactions, specifically manufactured defaults. By requiring a causal link between the issuer's failure to pay and a deterioration of its creditworthiness or its financial condition, the Amended Definition restores the connection between the issuer's risk of default and its credit risk that CDS are expected to reflect. Thus, the Amended Definition would assist in reestablishing the informational value of CDS spreads to the market and disincentivize counterparties from engaging in manufactured defaults. Rather than trying to account for all possible future iterations of manufactured defaults, the Amended Definition opts for a non-exhaustive list of factors that the Determinations Committee can consider, injecting

247 INT'L SWAPS \& DERIVATIVES ASS'N, PROPOSED AMENDMENTS TO THE 2014 ISDA CREDIT DeRIVATIVES DEFinitions Relating to NARRowly TAILORED CREDIT Events (2019), https://www.isda.org/a/CKeME/20190320-NTCE-consultation-doc-complete.pdf.

248 Id.

249 INT'L SWAPS \& Derivatives ASS'N, 2019 NARRowly TAILORED CREDIT EVENT SUPPLEMENT TO THE 2014 ISDA CREDIT DERIVATIVES DEFINITIONS $§ \quad 2$ (2019), https://www.isda.org/a/KDqME/Final-NTCE-Supplement.pdf.

$250 \quad I d . \S 3 \rrbracket 1.4$.

251 Id. $\S 3 \rrbracket 1.10$ 
subjectivity into the decisionmaking process. ${ }^{252}$ Thus, the Determinations Committee is empowered to investigate the underlying transaction, which may violate the spirit of the CDS contract, rather than solely interpreting the letter of the contract.

By authorizing the Determinations Committee to determine whether a default constitutes a valid, contractually recognizable Failure to Pay, the Amended Definition notably veers away from ISDA's traditionally textualist approach to the Master Agreement. ${ }^{253}$ The Amended Definition permits the Determinations Committee to consider the underlying purpose of the transaction that resulted in the issuer's default in deciding whether there is a contractually obligated credit event. ${ }^{254}$ Notably, ISDA has introduced greater ambiguity into the Master Agreement with the possibility of a Determinations Committee investigation to identify contractually acceptable instances of default, rather than strict interpretation of the contract's terms. It must be noted that the inexactitude of the Amended Definition is a strength, not a weakness. The strategies that CDS counterparties use today to engineer CDS transactions may not be the strategies that they use tomorrow or next year. The subjectivity inherent in the Amended Definition provisions, therefore, provides the Determinations Committee with needed leeway to address future iterations of manufactured defaults that fundamentally divorce credit risk from default risk.

Despite these positive attributes, ISDA's amendments are incomplete and do not provide a comprehensive response to engineered transactions. The Amended Definition provides a mechanism by which manufactured defaults are invalidated, but it fails to do the same with respect to transactions aimed at avoiding or negating CDS default. While it may be arguable that manufactured defaults are the most egregious of the three forms of engineered transactions, it is undeniable that the other forms of engineered CDS transaction are likewise costly to the markets. In failing to address the means by which counterparties can avoid and negate defaults, the Amended Definition creates an opportunity for regulatory arbitrage in the CDS market. ${ }^{255}$ It is likely, therefore, that parties interested in guaranteeing the outcome of their CDS positions will employ strategies that are treated differently under the Amended Definition but economically have the same

252 INT'L SWAPS \& DERIVATIVES ASS'N, supra note 245, at $\S 3$ \1.9 (noting that factors set out for the Credit Deterioration Requirement are "not exhaustive").

253 See supra Section I.C.

254 INT'L SWAPS \& DERIVATIVES ASS'N, supra note 245, at § 3 ฯฯ1.9-1.11.

255 Victor Fleischer, Regulatory Arbitrage, 89 TEX. L. REV. 227, 230 (2010) (defining regulatory arbitrage as the "manipulation of the structure of a deal to take advantage of a gap between the economic substance of a transaction and its regulatory treatment"); Hossein Nabilou, Regulatory Arbitrage and Hedge Fund Regulation, 22 FORDHAM J. CORP. \& Fin. L. 557, 563 (2017) ("[R]egulatory arbitrage, broadly defined, refers to shifting activities from a heavily regulated financial sector to an unregulated or lightly regulated financial sector with the aim of maximizing profits by taking advantage of regulatory differentials."). 
result. Thus, while the Amended Definition diminishes the incentives to manufacture CDS defaults, it simultaneously heightens the attractiveness of transactions aimed at avoiding and negating defaults for protection sellers.

Even with regards to manufactured defaults, the Amended Definition has shortcomings. The Determinations Committee is empowered to decide whether a Failure to Pay constitutes a valid credit event, but it is not required to consider external factors. In granting the option to the Determinations Committee to elect whether or not to consider outside factors, the Amended Definition weakens the efficacy of its proscription. In light of ISDA's historically textualist approach to the Master Agreement, allowing the Determinations Committee to make that choice may result in a continued formalistic approach in recognizing whether a credit event has occurred, especially for more ambiguous cases. Along the same vein, while it is laudable that the Amended Definition's list of factors that may indicate that a default is engineered is non-exhaustive, it is important that the Determinations Committee take a capacious view of its authority to invalidate manufactured defaults. Undoubtedly, the effectiveness of the Determinations Committee in proscribing manufactured defaults hinges in large measure not only on its ability to recognize evolutions in the form of these transactions but, importantly, on its willingness to identify as impermissible those transactions that are not explicitly listed.

The Amended Definition is a meaningful starting place for ISDA to address engineered transactions, but its limited scope restricts the efficacy of its prohibitions. In focusing exclusively on manufactured defaults, the Amended Definition leaves the other two strategies available to counterparties who want to engineer their CDS' outcomes, thereby heightening the possibility of arbitrage. Thus, owing to its narrow focus, it is questionable how effective the Amended Definition can be in limiting the net negative costs associated with engineered CDS transactions in the market.

\section{$\mathrm{V}$}

\section{PATHWAYS FORWARD: ADDRESSING THE GAP}

The existing gap in the law applicable to CDS in providing a comprehensive response to engineered CDS transactions threatens the viability of the CDS market. To minimize the far-reaching consequences of engineered CDS transactions, it is necessary to consider how to address the ills attendant to engineered CDS without destroying the benefits of CDS on which the market relies. Part V recommends three proposals aimed at limiting the pernicious effects of engineered CDS transactions. Broadly, the Article's proposals include broadening the scope of ISDA's amendments, implementing contractual changes to the Master Agreement, and reconceptualizing a key element of market anti-manipulation laws. Each is 
detailed below.

\section{A. Broadening the Scope of ISDA's Amendments}

The Amended Definition provides a valuable template for how we ought to consider implementing changes to address engineered transactions. To most effectively limit the availability of engineered transactions, contractual amendments ought to be open-ended and, ultimately, grant a decisionmaker flexibility to identify ever-evolving engineering strategies. In this regard, the Amended Definition relies on the Determinations Committee to assess the contractual validity of a default by examining whether it undermines the essential purpose of CDS, even if it complies with the letter of the Master Agreement. Yet to be more impactful, the Amended Definition must be expanded. Specifically, the form and process by which engineered transactions are invalidated needs to be more robust and not only limited to manufactured defaults.

To meaningfully expand the Amended Definition requires careful consideration of whether the Determinations Committee, as currently comprised, is best suited to identify and address engineered transactions. Although it seems reasonable to empower the Determinations Committee to investigate engineered transactions, there are legitimate concerns that arise from relying on the Determinations Committee. Traditionally, the Determinations Committee has taken a textual and formalistic approach to its interpretation of the Master Agreement, and, it will continue to do so for all clauses except the Amended Definition. This creates a dichotomy regarding how the Determinations Committee will fulfill its mandate and may result in the Committee doing neither job particularly well going forward. One option to address the Determinations Committee's bifurcated mission could be to expand its authority, such that it has broader investigatory and interpretative authority over the Master Agreement. This option could improve the Determinations Committee overall operation; however, such an expansion would subsume the Determinations Committee, transforming it into an entirely different body. Another option could be to form a separate decisionmaking body with a broader mandate to complement the Determinations Committee. This Article supports the latter route and proposes that ISDA form a separate "Adjudicatory Committee" authorized to assess whether transactions or counterparty conduct violates the spirit, even if not the letter of the Master Agreement.

The Adjudicatory Committee would have responsibility for ex ante and ex post interpretive questions regarding the Master Agreement and its application among CDS counterparties. It would provide market participants with a mechanism by which to challenge the validity of engineered transactions within ISDA's framework. For example, it would consider whether the last-minute loan to RadioShack ought to be treated as a default 
(as parties had argued in their petition to the Determinations Committee) given the conflict of interest of the lender. ${ }^{256}$ Notably, the Adjudicatory Committee would be required to investigate and make a decision on questions it receives regarding ex ante interpretation or ex post application of the Master Agreement. From an ex ante standpoint, the Adjudicatory Committee would be empowered to answer interpretive questions regarding the scope, applicability, or interpretation of the Master Agreement. Ex post, it would evaluate whether an event constitutes a contractually valid credit event, an effort to avoid an issuer's default, or negates future default under the Master Agreement.

In making ex post decisions, the Adjudicatory Committee's role would overlap with that of the Determinations Committee because it would be deciding whether a credit event occurred based on contextual analysis of the transaction and other extraneous evidence. However, the proposed Adjudicatory Committee and the Determinations Committee would be able to coexist with little issue under the Article's proposal for two reasons. First, the Determinations Committee would remain the initial decisionmaker as to whether a credit event has occurred. Second, the Adjudicatory Committee would only intervene if (i) the Determinations Committee decided that additional considerations ought to be taken into account in making its decision, or (ii) a CDS counterparty alleged that a transaction was improperly engineered. Thus, the Adjudicatory Committee would complement the work of the Determinations Committee and would not be superfluous or redundant within ISDA's current framework.

Further, the Adjudicatory Committee's role as the official interpreter of the Master Agreement would also serve to eliminate potential sources of ambiguity before they are exploited or wreak havoc in the CDS markets. More broadly, the Adjudicatory Committee would provide the CDS market with the internal structure to interpret and enforce the Master Agreement. Currently, this is lacking in the CDS market and would only be introduced on a limited basis through the Amended Definition - not nearly widescale enough to meaningfully address engineered transactions and similarly exploited loopholes in the Master Agreement. By establishing an internal adjudicatory and interpretive body, ISDA would have a more streamlined mechanism through which it can assert its preferred interpretation of the Master Agreement, particularly if a court later hears the dispute. Formation of the Adjudicatory Committee would allow ISDA, as the standard setter and drafter of the Master Agreement, to be the definitive voice with respect to the interpretation and enforcement of the Master Agreement's terms and clauses. If market participants know that they can petition the Adjudicatory Committee for an official interpretation of what a clause means or what it

256 See supra Section II.B. 
permits, this would increase predictability and certainty in the market. Further, a potential indirect consequence of the Adjudicatory Committee would be less regulatory scrutiny of the industry and its trading strategies. In proactively embracing an enforcement mechanism to review and possibly reject engineered transactions, ISDA would be providing regulators with some assurances that it was addressing these problematic transactions, thereby staving off regulatory interference in the market.

Creating an Adjudicatory Committee would expand the capacity of the CDS market to respond to engineered transactions-whether they are in forms currently known or in iterations yet unknown. Moving away from a formal, textual approach to the Master Agreement is necessary to accommodate the evolution and development of the CDS market. The Adjudicatory Committee would expand on the Amended Definition by granting greater flexibility to the decisionmaker to examine transactions to verify whether they conform with both the spirit of the Master Agreement and the purpose of the CDS contract. Further, the Adjudicatory Committee would enable ISDA to protect the market's integrity in the face of potentially exploitative transactions that undermine the essential purpose of CDS as financial instruments.

Although implementation of an Adjudicatory Committee would provide a direct path to respond to engineered CDS transactions, it is not without potential shortcomings. One issue with the Adjudicatory Committee is that it may add ambiguity and complexity to the CDS market. While it is true that the Adjudicatory Committee would rely on a contextual analysis to decide whether a credit event has occurred, it is not true that a contextual analysis is more unpredictable than a formalistic textual analysis, especially when the latter results in economically unsound conclusions. ${ }^{257}$ Further, the Adjudicatory Committee's purview would be limited to complex cases involving allegations of engineered transactions or contractual ambiguity, not to all considerations of whether there is a credit event. Thus, concerns that the Adjudicatory Committee would needlessly complicate the markets are overstated.

The establishment of an Adjudicatory Committee would raise noteworthy concerns about the power and authority of ISDA in the CDS markets, particularly given that it is subject to little to no regulatory oversight or public accountability. Adding the Adjudicatory Committee to ISDA's framework could increase the trade association's dominance over the CDS market and, by extension, market actors that are powerful within ISDA. A significant concern with adding to the ISDA governance framework is that it would be captured by politically powerful actors within the markets, thereby diminishing its utility as a bulwark against engineered transactions.

257 See supra Section I.C. 
Owing to political realities within ISDA, it is possible that the Adjudicatory Committee would not be effective in reducing engineered transactions; and that, instead, it would serve the interests of the most powerful in these disputes. However, given the preferences of CDS market participants to avoid government intervention, it is just as likely that the Adjudicatory Committee would try to be more-or-less even-handed in its decisionmaking to obviate regulatory scrutiny.

\section{B. (Re)Establishing Good Faith Obligations}

To date, courts have not interpreted whether the implied covenant of good faith and fair dealing prohibits engineered transactions specifically. However, in light of the court's holding in Good Hill and similar cases involving the applicability of the covenant of good faith in the Master Agreement, there is a strong likelihood that courts may not view the implied covenant as proscribing engineered transactions. This Article proposes imposing disclosure obligations on swap dealers, which will indirectly establish good faith obligations, despite the Self-Interest Provision and provide an indirect way to limit the feasibility of engineered CDS.

As the primary intermediaries in the CDS markets, it is likely that a CDS counterparty that engages in engineered CDS transacted with a swap dealer - either the CDS counterparty bought or sold CDS from a swap dealer or a swap dealer intermediated the transaction between the CDS counterparty and another party. It may be possible to indirectly regulate engineered CDS through requirements that are imposed on swap dealers that affect their CDS transactions with counterparties. There are two possible avenues through which this may be accomplished.

First, in executing CDS transactions, swap dealers must obtain representations and warranties from their counterparties and ensure that the transactions comply with the respective Commission's regulations. Notably, since these representations and warranties were the result of the Dodd-Frank Act and were not contemplated in the ISDA Master Agreement, ISDA published DF (Dodd-Frank) Protocols 1.0 and 2.0 to facilitate compliance with new CFTC regulations. ${ }^{258}$ To regulate engineered CDS, the Commissions could require swap dealers to include a prohibition against these types of transactions among their representations and warranties. By including a prohibition against engineered transactions within the representations and warranties, the Commissions could indirectly limit the availability of these transactions to CDS traders. Further, to the extent a counterparty breaches the covenant, she could be subject to enforcement

258 InT'L Swaps \& Derivatives Ass'N, ISDA MARCh 2013 DF PROTOCOL AgReEMENT (2013), http://assets.isda.org/media/38756a02/7ecb18ba-pdf. 
actions from the Commissions for failing to comply with the regulations, and she could also face a private cause of action for breach of contract.

Second, under the Commissions' business conduct rules, swap dealers are required to disclose any "material incentives or conflicts of interest" that they have with respect to the transaction to their non-swap dealer counterparties. ${ }^{259}$ Further, they are required to communicate with counterparties fairly and in keeping with the principles of fair dealing and good faith. ${ }^{260}$ These provisions are intended to protect swap dealers' counterparties, particularly non-dealers such as pension funds or municipalities, but could be expanded to reach the conduct of all CDS counterparties that transact with swap dealers. In order to accomplish this, the requirement to disclose material incentives and conflicts of interest should flow equally between both parties and not merely from swap dealers to non-dealer counterparties. To prevent the disclosure obligation from being too onerous, it would be limited to material incentives or conflicts that may affect or trigger the CDS payout. The disclosure obligation would also accompany future trades of the CDS such that the information is available to later counterparties. By requiring disclosure of plans to engage in an engineered CDS transaction, traders are able to reject counterparties that have indicated their intentions to intervene in the market. Alternatively, it allows CDS traders to decide if they want to charge or demand a higher price from the counterparty to offset the risk of loss. Disclosure, therefore, minimizes informational asymmetry between the counterparties, which would increase the cost of engineered transactions and in turn lower their profitability and their occurrence. Additionally, this disclosure requirement may also enhance market discipline, enabling CDS traders to avoid counterparties that might engage in engineered transactions or have done so in the past.

By imposing either or both of these contractual provisions on swap dealers, the regulators would be able to cabin the availability of engineered transactions to the market. A contractual proscription on engineered transactions or a disclosure obligation with respect to conflicts of interests would introduce an additional contractual clause into the CDS transaction that would have to be balanced against the Self-Interest Provision. Thus, the ability of CDS counterparties to act in a self-interested manner would have as the outer limit their obligations to refrain from engineering outcomes and to disclose relevant conflicts. This would establish the applicability of good faith and fair dealing as a meaningful restriction on strategic behavior that undermines the value and purpose of CDS to the market. Relatedly, this proposal would increase the costs of engineered CDS for their proponents because it would increase the difficulty of finding counterparties with whom

25917 C.F.R. $\S 23.431(\mathrm{a})(3)$ (2018).

260 Id. $\S 23.433$ 
to trade and increase the probability of successful lawsuits challenging the transaction.

Despite these positive attributes, this proposal has shortcomings that limit its effectiveness. Specifically, this would be an indirect way to address engineered transactions. It places the burden on swap dealers, who are unlikely to engage in engineered CDS, rather than on CDS counterparties directly. ${ }^{261}$ Indirect regulation oftentimes is accompanied by unconsidered collateral consequences within the markets. Such unexpected effects often manifest after it is too late and sometimes in ways that may have made the cure worse than the original disease. For instance, the disclosure requirement this Article proposes could be utilized by market participants to engage in strike suits, to attempt to gain access to information that is beyond the scope of what is considered here, or some other improper reason. Indirect regulation of the contractual terms of the CDS, therefore, could morph into a host of other issues that leave the market worse off than before. For this reason, whenever possible it is preferable to regulate directly rather than indirectly. Yet, this proposal would increase transparency in a notoriously opaque market. It would also better allow counterparties to enforce their contractual rights, either to disclosure or good faith conduct, thereby dissuading potential CDS engineers from undertaking the transaction.

\section{Redefining Artificiality}

The Article's final proposal to respond to engineered transactions rests in expanding how price artificiality is defined under the anti-manipulation laws. This is the broadest of the Article's three proposals and aims to modernize how the legal framework addresses modern trading strategies that distort the markets through per se legitimate conduct. The price artificiality standard is one of the original anti-manipulation provisions under both the securities and commodities regulatory regime. The proscription was adopted in the 1930s, and while the markets have evolved in ways that could not have been predicted, the price manipulation prohibition has not experienced similar expansion. As the law has failed to keep pace with the markets, legal gaps exist for conduct that has the same impact as traditional market manipulation schemes but utilizes modern-day trading strategies.

Although the author believes that Congress and the Commissions

261 There are a few reasons why swap dealers are unlikely to engage in engineered transactions. First, participating in these transactions would harm their reputational capital and as identifiable counterparties in the market, CDS traders would refuse to transact with a swap dealer knowing that it has a reputation for engineering. Therefore, any profits earned from engaging in an engineered transaction would be eroded through a loss of CDS business. Second, for regulatory reasons, as market makers swap dealers are required to maintain as neutral a position as possible in order to not run afoul of the Volcker Rule. 12 U.S.C. § 1851 (2012); Prohibitions and Restrictions on Proprietary Trading and Certain Interests in, and Relationships with, Hedge Funds and Private Equity Funds, 79 Fed. Reg. 5536 (Jan. 31, 2014) (to be codified at 17 C.F.R. pt. 255). 
should modernize several other aspects of the market manipulation framework, the Article focuses narrowly on expanding the price artificiality standard in proposing changes to the anti-manipulation framework because of its direct applicability to engineered transactions. Engineered transactions decrease the price efficiency of the markets by distorting the informational value of the CDS spread. While there is harm to the market and the prices are less accurate, under existing anti-manipulation laws, this does not constitute market manipulation. Thus, the price artificiality standard should be expanded to consider how a transaction impacts the information being reflected in the price, even if the transaction is per se permissible, as is the case with engineered transactions.

Traditionally, in deciding whether a price is artificial, courts rely on one of two approaches. A court may consider a price to be artificial if it either (i) does not reflect legitimate forces of supply and demand; ${ }^{262}$ or (ii) deviates from its historical or expected value. ${ }^{263}$ Implicit in both formulations is the assumption that the price is artificial because of illicit conduct that interferes with supply and demand or that results in deviation from what is expected. And, in the absence of illicit conduct, transactions constitute price manipulation only if the trader had manipulative intent when transacting. ${ }^{264}$ As the author has argued in other scholarship, the legitimacy of a transaction ought not to shield it from being considered as potentially artificial. ${ }^{265}$ Indeed, per se legitimate conduct can distort the information reflected in the price of the asset, sending inaccurate and artificial signals to the market. Thus, if we take seriously the proposition that permissible conduct can create price artificiality because it distorts market pricing, then it can be argued that engineered transactions result in price artificiality. But, to make this argument, we must expand the legal conception of what it means for a price to be artificial, particularly with respect to per se legitimate conduct.

This Article contends that engineered transactions create an artificial price because they interfere with the legitimate market forces that ought to establish the CDS spread. Consider that the market's response to news of an engineered CDS is expected, but this does not make it a legitimate force within the market. An engineered transaction is designed to alter the payout of the CDS contract and guarantee the profitability of one trader's positions. As such, the intervention of a CDS counterparty to engineer the outcome of the CDS is an improper and illegitimate market force that results in an artificial price. The permissibility of the engineered transaction from a

262 See Wendy Collins Perdue, Manipulation of Futures Markets: Redefining the Offense, 56 FORDHAM L. REV. 345, 370 (1987) (“Another approach defines artificial price as a price that does not reflect the 'basic' or 'legitimate' forces of supply and demand.").

263 Id. at 367 ("[A]n artificial price is one that is historically unusual, either because of its absolute level or because of its relationship to other prices.").

264 See supra Section IV.A (discussing the law regarding open-market manipulation).

265 Fletcher, supra note 170, at 517. 
contractual standpoint should not be confused with its legitimacy as an influence on the price of the CDS. In the absence of the engineered CDS, the value of the instrument would be determined by the vicissitudes of the referenced asset; however, because of the engineered CDS, the price is made artificial. The engineered transaction impedes the market's ability to assess the default risk of the issuer based on its financial condition. Thus, practically and realistically, the price is artificial because it is set through illegitimate, even if permissible, market considerations.

Additionally, engineered transactions cause CDS prices to deviate from their historical and expected value because they distort the information reflected in CDS spreads. Post-engineering, the CDS spread reflects the likelihood of success of the engineered transaction, rather than default risk connected to financial condition. The CDS spread historically does not reflect this information nor is it the default risk that the market expects to be reflected in the transaction. Yet, once an engineered transaction has been announced, the CDS spread reflects the probability of the negotiated outcome between the issuer and the CDS counterparty, not the risk of default associated with the issuer's financial condition. Again, the contractual acceptability of the engineered transaction does not render the resulting price true. Rather, engineered transactions result in CDS prices sending distorted signals to the markets regarding the issuer's risk of default, given that default risk is no longer connected to financial condition.

Redefining price artificiality in this way would provide the Commissions with an effective tool to respond to engineered CDS and punish those who participate in these transactions. Importantly, this Article's proposal to expand the conception of price artificiality would not require legislative change; rather, it would require the Commissions to alter their theory of liability for price artificiality. Regulators have, in the past, changed their analysis and application of laws and regulations in response to market changes and developments. For example, in the realm of insider trading, the SEC extended its theory of insider trading to recognize liability if the trader "misappropriated" information and traded on this information in violation of a fiduciary duty owed to the source. ${ }^{266}$ This extension of the insider trading was novel and had not been part of the historical bases of liability for insider trading. But, importantly, it was not beyond the scope of the agency's legislative authority to prosecute insider trading. The misappropriation theory of insider trading did not contradict prior law or statutory authority; it merely extended the application of the law to other scenarios using a new theory.

Similarly, altering the theory of liability for price artificiality would not be beyond the Commissions' authority. However, given that it would be a

266 United States v. O’Hagan, 521 U.S. 642, 648-49 (1997). 
change to how the Commissions apply previously existing standards, the Commissions are likely to face significant resistance from the courts in their new standards. With decades of precedent defining what constitutes an artificial price, altering the theory of liability is likely to be difficult without legislative support. Thus, legislative changes would provide the Commissions with an acceptable explanation for their redefinition of price artificiality when being challenged in court. However, changes that would depend on an act of Congress and that would increase liability for the market are not likely to be well-supported or feasible at this juncture. In sum, expanding the definition of artificiality would address engineered transactions directly and modernize the anti-manipulation framework but the lack of political will makes this path an unlikely one at this time.

\section{CONCLUSION}

Notwithstanding their negative reputation, CDS are useful financial products that enhance pricing efficiency, increase market liquidity, and increase the availability of credit to companies. With CDS, investors are able to offset their risk exposure and companies can more easily gain access to capital. To fulfill these laudable benefits, CDS ought to reflect an issuer's risk of default due to its financial condition. Engineered transactions, however, remove the risk of default as one counterparty unilaterally decides when and if a company defaults to guarantee its CDS positions' profitability. Default no longer becomes an uncertain risk but is guaranteed to occur (or not) based on the counterparty's CDS positions. When CDS traders are allowed to bypass market forces to guarantee profits on a transaction, the markets suffer - pricing becomes inefficient and liquidity is negatively impacted. Further, engineered transactions impose costs on market actors unaffiliated with the CDS market and undermine the public's trust in the financial markets. Engineered CDS transactions, therefore, are detrimental to the markets, imposing negative externalities on the markets that outweigh their limited benefits.

The existing public and private frameworks applicable to CDS, however, are ill-suited to effectively address engineered transactions. As financial instruments based on a privately crafted boilerplate contract, CDS are subject to anti-manipulation laws and regulations and contract common law, neither of which limit the availability of engineered transactions. ISDA has amended the Master Agreement in response to engineered transactions, but owing to the narrowness of the amendments, they do not effectively combat engineered transactions. Thus, engineered transactions continue to impose significant negative externalities on third parties, undermining the utility and viability of the CDS markets.

As the markets continue to innovate in ways that may distort and disrupt the efficiency of the markets, it is incumbent on the law to keep pace with 
constantly evolving yet distortive practices, like engineered transactions, that escape the reach of existing approaches. To this end, this Article proposes a range of legal responses, each aimed at responding to engineered transactions and safeguarding the future of the CDS markets. By taking a forward-looking approach to the CDS markets, this Article recommends flexible, capacious solutions to engineered transactions designed to address current and future iterations of these schemes. This Article proposes three potential legal responses to minimize the availability of engineered transactions, which range in terms of both difficulty of implementation and comprehensiveness. Fundamentally, however, this Article challenges lawmakers and regulators to recognize the need for modernization of the market manipulation framework, which remains crucial to minimizing the impact of innovative distortions on the markets going forward. 